\title{
An Evaluation of the Effectiveness of A Multidisciplinary Pain Management Intervention for Rural Adults with Chronic Pain
}

\author{
Cathy McCoy
}

Follow this and additional works at: https://researchrepository.wvu.edu/etd

\section{Recommended Citation}

McCoy, Cathy, "An Evaluation of the Effectiveness of A Multidisciplinary Pain Management Intervention for Rural Adults with Chronic Pain" (2016). Graduate Theses, Dissertations, and Problem Reports. 6196. https://researchrepository.wvu.edu/etd/6196

This Dissertation is protected by copyright and/or related rights. It has been brought to you by the The Research Repository @ WVU with permission from the rights-holder(s). You are free to use this Dissertation in any way that is permitted by the copyright and related rights legislation that applies to your use. For other uses you must obtain permission from the rights-holder(s) directly, unless additional rights are indicated by a Creative Commons license in the record and/ or on the work itself. This Dissertation has been accepted for inclusion in WVU Graduate Theses, Dissertations, and Problem Reports collection by an authorized administrator of The Research Repository @ WVU. For more information, please contact researchrepository@mail.wvu.edu. 
An Evaluation of the Effectiveness of

A Multidisciplinary Pain Management Intervention for Rural Adults with Chronic Pain

\author{
Cathy McCoy FNP-BC \\ Doctoral Capstone Project submitted \\ to the School of Nursing \\ at West Virginia University \\ in partial fulfillment of the requirements for the degree of \\ Doctor of Nursing Practice in \\ School of Nursing
}

Susan McCrone, PhD, Chair

Martha Summers, DNP

Dr. Fahim, MD, PhD

Department of School of Nursing

Morgantown, WV

2016

Keywords: chronic pain management, adults, anxiety, depression, quality of life.

Copyright 2016 Cathy McCoy FNP-BC 


\begin{abstract}
An Evaluation of the Effectiveness of

A Multidisciplinary Pain Management Intervention for Rural Adults with Chronic Pain Cathy McCoy FNP-BC
\end{abstract}

Chronic noncancerous pain (CNCP) is a major health problem in West Virginia (WV). Legislative barriers have limited primary care providers on the number of $\mathrm{CNCP}$ patients they can treat within their practice. Consequently, many patients have lost treatment for their chronic pain and chronic illnesses. Providers have refused to accept new patients with preexisting chronic pain and discharged those within their practices to stay under the limits of the law. A large number of pain patients began to go to local emergency rooms for pain management and untreated chronic illnesses. A multidisciplinary chronic pain management center has the potential to improve care and provide pain management allowing primary care providers to exclusively treat chronic illnesses. The primary goal of this project was to evaluate the effectiveness of a multidisciplinary pain intervention on quality of life (QOL), anxiety, depression, and pain in rural adults with $\mathrm{CNCP}$. Using a pretest/posttest design, 107 participants were evaluated on QOL, anxiety, depression, and pain prior to entering a six month multidisciplinary pain management program. Options of five interventions, (i.e., physical therapy, mental health assessment, psychological counseling, individual educational sessions with a registered nurse (RN) monthly, and pain specialty interventions), were given to participants. The sample was required to complete three of the five multidisciplinary interventions within 6 months before posttest scores were considered for the evaluation. All participants received primary care for their chronic illnesses outside of the pain management center during their participation in the 
program. Paired sample t-tests demonstrated that there was a statistically significant decrease in anxiety, depression, and pain scores, and an increase in QOL from pretest to posttest. 


\section{Executive Summary}

Background: Several clinical guidelines agree that the use of chronic opioid therapy (COT) and opioid risk, mitigation stratification along with psychotherapeutic interventions, functional restoration, interdisciplinary therapy, and other adjunctive non-opioid therapies can be effective in treating carefully selected and monitored patients with chronic noncancerous pain $(\mathrm{CNCP})$.

Objective: To determine if multidisciplinary interventions provided in a pain management center integrating evidence based guidelines improved QOL, anxiety, depression, and pain in a sample of rural adults in WV with CNCP.

Design: Using de-identified data, this study evaluated the effectiveness of a 6 month pain management program on self-reported QOL, anxiety, depression, and pain in 107 participants. Paired t-tests were used to calculate pretest/posttest score differences. The multidisciplinary team members within the program's design included: physical therapists (PT), professional counselors, primary care providers (PCPs), registered nurses (RNs), nurse practitioners (NPs), overseeing physicians, and a pain specialty interventionist. Program components consisted of: a history and physical, diagnostic testing, substance risk assessment, assessments of self-reported anxiety, depression, quality of life, and pain, monthly patient education, functional restoration, COT per the overseeing physician with NP monitoring, chronic illness management per primary care provider, and a pain interventionist consult on non-opioid approaches for pain control. For evaluative data to be considered, participants must have completed three out of five interventions. These interventions included: physical therapy sessions, a mental health assessment, psychological counseling sessions, pain specialty consult for non-opioid approaches in pain, and educational sessions with the RN. The intervention involving educational sessions 
with the RN was offered with each monthly medical visit to the clinic. The $\mathrm{RN}$ offered education and handouts in the following areas: diet and exercise, physiological process of degenerative disc disease and disc herniation, osteoarthritis verse rheumatoid arthritis, smoking cession and second hand smoke exposure, constipation, medication storage safety, and driving while under the influence.

Results: Measurements of self-reported QOL, anxiety, depression, and pain were taken pre and post program implementation. The Short Form-Health Survey (SF-36v2), The Beck Anxiety Inventory (BAI), The Beck Depression Inventory (BDI), The Center for Epidemiologic Studies Depression Scale (CES-D), and The McGill Pain Questionnaire were used to measure the outcomes. Analyses were conducted on SPSS for Windows version 10. Paired sample t-test compared pretest/posttest scores of 107 participants completing three out of five interventions. Among the 107 participants, females comprised $56.1 \%$ of the group with the male sample percentage being $43.9 \%$. The mean age for the sample was 53.76 years of age (SD, 11.579) with a range of 29-86 years. The entire sample was Caucasian. The race reflected the composition of the community. Unemployment percentages among the sample were high at $93 \%$. The majority of the sample was single and comprised $51 \%$ of the group, while the other $49 \%$ were married at the time of participation.

The participants' QOL was evaluated at pre- and post-intervention with the SF36v2 scale to assess participants' perceptions of their QOL in the Mental Component Score (MCS) and Physical Component Score (PCS). There was a statistically significant increase in MCS scores from pre-program scoring $(M=41.71, S D=14.50)$ to post program scoring $(M=49.87, S D=12.08)$. The mean increase in MCS scores was -8.1327 with a $95 \% \mathrm{CI}=10.62$ to -5.70 . The eta squared statistic (-0.29) indicated a large effect size. Likewise, there was a statistically significant 
increase in PCS scores from pre-program scoring $(M=24.83, S D=8.92)$ to post program scoring $(M=28.13, S D=10.71)$. The mean increase in PCS scores was -3.29 with a $95 \% \mathrm{CI}=-5.00$ to -1.58. The eta squared statistic (-0.16) indicated a large effect size. These two results demonstrated an overall significant difference in the QOL scores in the mental as well as the physical aspects.

Participants completed the Beck Anxiety Index (BAI) pre- and post-intervention to assess participants' perceptions of their anxiety. Results revealed a significant decrease in BDI scores $(t(106)=1.65, p<.05,95 \% \mathrm{CI}=4.241$ to 7.964$)$ from pre-program $(M=16.73, S D=10.91)$ to post program $(M=10.63, S D=7.75)$. The mean decrease in BAI scores was 6.10 with a $95 \%$ $\mathrm{CI}=4.24$ to 7.96 . The eta squared statistic (0.30) indicated a large effect size with a substantial difference in the anxiety scores.

Participants also completed the Beck Depression Inventory (BDI) and the Center for Epidemiologic Studies Depression Scale (CES-D) to assess participants' perceptions of their depression. There was a statistically significant difference in BDI scores $(t(106)=1.65, p<.05$, $95 \% \mathrm{CI}=1.73$ to 4.39$)$ from pre-program $(M=12.51, S D=8.80)$ to post program $(M=9.45$, $S D=8.13$ ). The mean decrease in BDI scores was 3.06 with a $95 \% \mathrm{CI}=1.73$ to 4.39 . The eta squared statistic (0.17) indicated a large effect size. Likewise, there was a statistically significant decrease in CES-D scores from pre-program $(M=16.43, S D=10.82)$ to post program $(M=10.17$, $S D=8.80)$. The mean decrease in CES-D scores was 6.25 with a $95 \% \mathrm{CI}=4.53$ to 7.97 . The eta squared statistic (0.30) indicated a large effect size as well. These two results demonstrated equally an extensive difference in the depression scores obtained from before to after the intervention. 
The last outcome was the McGill Pain Questionnaire to assess participants' perceptions of their pain. There was a statistically significant decrease in pain scores from pre-program $(M=36.21, S D=11.78)$ to post program $(M=29.24, S D=10.73)$. The mean decrease in pain scores was 6.96 with a $95 \% \mathrm{CI}=4.66$ to 9.25 . The eta squared statistic (0.29) indicated a large effect size thereby validating a vital difference in the pain scores.

Conclusion: A multidisciplinary pain center instituting evidenced based guidelines with risk migration strategies was effective in improving QOL, anxiety, depression, and pain perceptions in rural adults with $\mathrm{CNCP}$.

Recommendations: Dissemination of these results with regards to the multidisciplinary pain model are recommended to increase the continuum of care for chronic illness in CNCP patients in $\mathrm{WV}$, to heighten multidisciplinary approaches in management of $\mathrm{CNCP}$, and to improve access for rural WV's population to specialty care for CNCP. 


\section{Dedication}

The dedication of this work extends to my children and husband. For the longest time in my youth, I questioned the differences and similarities of gifts and natural talents. I came to believe with adulthood that gifts and talents were misunderstood for hard work and determination for success. Then I meet my husband, and my three children came to be. The things my children were able to achieve so easily and without effort made me reconsider things I had once questioned. My eldest son had an uncanny leadership quality that surfaced in preschool. He nurtured that talent throughout his high school years taking his football team as a quarterback to a state level. He continued in college completing his BSN and critical care certification. With growth in efficiency, his talent has taken him to a CRNA program in Pennsylvania within the first 2 years of his RN career. He has a true gift intended to be used on the behalf of others. Endurance was the talent of my middle son. As an outstanding distance runner, I watched him set record after record and run at a collegiate level while majoring in chemistry for medical school. As a result of his efforts, he is now a fourth year medical student at WVU and applying to residency programs. He intends to use his gift within a teaching hospital for the good of others. My youngest, a daughter, was bestowed with the talent of courage. Her motto is to face your fears and get the job done. Singing in five languages at the age of nine on stage for groups of 5,000 people at a time enhanced her talent of fearlessness and led her into a nursing degree with a premed background. Her gift has given her a strong sense of patient advocacy that will go to benefit those in need. Through these witnessed talents that were enriched for the good of others, I came to believe that I must be cut from the same cloth as my family. I hope that I have put all my talents into this paper and my career for the benefit of others and that I have reached the bar my children have set for me. 


\section{ACKNOWLEDGEMENTS}

The completion of this project could not have happened alone. Gratitude goes out to each person that has made this goal possible.

- To my committee member, Dr. Susan McCone, Dr. Martha Summers, and Dr. Mohamed Fahim- words cannot express the appreciation I have for all your time vested, for all your discernment entrusted, and for all your leadership instilled on my part to complete this expedition in my life. It is because of this, the end result is of the great magnitude that it is.

- To the loving memory of Dr. Heidi Putman, my original Chair - her life was taken due to cancer. How I loved to hear the stories you shared of your little boy and the angry birds.

- To the loving memory of Dr. Joe Boyce, a physician at the pain management center- his life was taken in a tragic car accident leaving from work at the center. An extreme admirer of Superman, you, Dr. Boyce, were a true superman in all aspects of life.

- To the hand-picked staff at the Physical Wellness and Rehabilitation Center- you witnessed the visual changes of our patients as a result of your passionate work to assist in multiple health care areas affected by CNCP. So many times I have heard how rewarding it was for you to work at this center. It is because of your motivation and hard work this project succeeded.

- To my loving husband who is always beside me in all endeavors-your support is invaluable. It is that support that allows me to give so much to others in need, hence your gift from the talent of deep love. 


\section{Table of Contents}

ABSTRACT

ii-iii

Executive Summary

iv-vii

Dedication

viii

ACKNOWLEDGEMENTS

ix

Table of Contents

x-xii

CHAPTER 1 INTRODUCTION

1

Background and Significance

$1-3$

Challenges to Enactment

4

Legislative Intervention

Impact of WV Legislation

Rationale for Intervention

9-10

Problem Statement

10-11

Theoretical Framework

11

Key Elements of Self-Efficacy

11-15

Project Description

16 
Literature Review and Synthesis

First Search Strategy

Study Identification

Data Abstraction and Process used

Second Search Strategy

Synthesis

Assumption

Potential Bias

Congruence of Organizations

CHAPTER III METHODOLOGY

Program Design

Instruments

Project Phases

Project Objectives

Evaluation
17-18

18-19

18-24

24

40-42

42-43

43

43-44

45

45

45-49

49-54

54-55

55

56

Patient Demographics

56-59 
Running head: CHRONIC PAIN MANAGEMENT: A MULTIDISCIPLINARY APPROACH

Program Impact on Outcomes

$59-61$

\section{CHAPTER V}

DISCUSSION, RECOMMENDATION, AND CONCLUSION $\quad \ldots . .61$

Discussion and Recommendations $\quad$......................... 61-62

Intervention Implementation: Evaluation of Effectiveness $\quad \ldots \quad 62-65$

Key Facilitators and Barriers $\ldots \ldots \ldots \ldots \ldots \ldots \ldots \ldots \ldots \ldots \ldots . \ldots \ldots$

Feasibility of Program Sustainability ...................... 66-67

Conveyance of the Theoretical Framework $\quad \ldots \ldots \ldots \ldots \ldots \ldots \ldots$ 6........ 67-68

Conclusion $\quad$............................................. 68-69

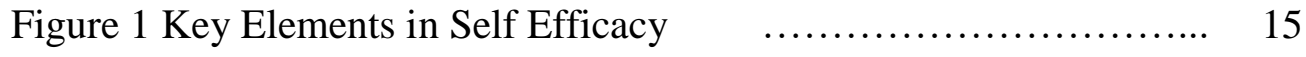

Figure 2 First Section Selection of Studies $\quad \ldots \ldots \ldots \ldots \ldots \ldots \ldots \ldots \ldots \ldots, 21$

Figure 3 Second Selection of Studies $\quad$...................... 39

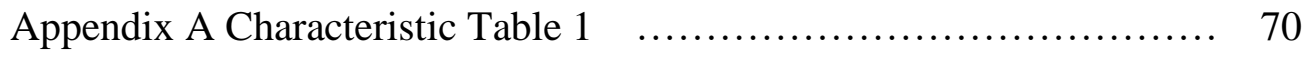

Methodological Qualities of CGs Table $2 \quad \ldots \ldots \ldots \ldots \ldots \ldots \ldots \ldots . \ldots . \ldots . \ldots 1$

Second Literature Review Articles Inventions and Outcomes $\quad \ldots \quad 72$

Reference $\quad$............................................ $73-86$ 


\section{CHAPTER 1 INTRODUCTION}

An Evaluation of the Effectiveness of

A Multidisciplinary Pain Management Intervention for Rural Adults with Chronic Pain

Although generally acknowledged, a routine definition for chronic pain has yet to be universally adopted. The International Association for the Study of Pain (IASP) defines this prevalent condition as pain that endures for 3 or more months (Johannes, Le, Zhou, Johnston, \& Dworkin, 2010). IASP organizes chronic pain according to classification (nociceptive versus neuropathic), body location, cause, neurophysiology, and the affected body system. Numerous effects contribute to the development of chronic pain including tenacious stimulation of nociceptors caused by destruction of local tissue from disease or an acute injury. This can further extend as a result of damage to the peripheral or central nervous systems, which is the underlying cause of neuropathic pain (Turk, Wilson, \& Cahana, 2011).

Pain is commonly divided into either acute or chronic pain. Acute pain is usually a warning signal of real or potential tissue damage, most evident as a result of accidental injury, inflammation and operative procedures. Fortunately, most acute pain conditions can be readily managed and will disappear after the traumatized tissue has healed (Sessle, 2011). It has been acknowledged though, that roughly $20 \%$ of acute pain disorders can evolve into chronic pain, which can be persistent or sporadic, especially if the acute pain is not properly treated (Lynch et al., 2008).

\section{Background and Significance}

Chronic pain affects people's well-being, their ability to maintain an independent lifestyle, productivity, and social relationships (Breivik et al., 2006). Predictably, depression and 
anxiety disorders have been found to be linked with chronic pain among medical patients in both developed and developing countries (Lepine \& Briley, 2004).

In patients with chronic pain, a decrease in functionality along with poor physical work tolerance and impaired quality of life are the long term results. Most problems arise from an increase in chronic pain levels or exacerbations with increased effort or exertion in daily activities. This, in turn, can result in immobility, dependence on others, and social isolation. A market research report (Global Industry Analysts, 2011) examined chronic pain of varying degrees. It reported that more than 1.5 billion people worldwide suffer from chronic pain and that approximately $3-4.5 \%$ of the global population suffers from neuropathic pain, with incidence rate increasing as populations age. According to Chrvala (2011), four US populationbased surveys estimated the prevalence of chronic pain at $14.6 \%, 30.7 \%, 36 \%$, and $64.4 \%$ (Johannes et al., 2010; Hardt, Jacobsen, Goldberg, Nickel, \& Buchwald, 2008; Portenoy, Ugarte, Fuller, \& Haas, 2004; Watkins, Wollan, Melton, \& Yawn, 2008). Differences in definitions, the populations surveyed, and methods of assessment contribute to these wide variations (Johannes et al., 2010). Nevertheless, it is clear that pain is the number one reason why people see their healthcare providers (Schappert \& Burt, 2006). A more recent publication identified that chronic pain is highly prevalent in the United States and Canada, occurring in an estimated $30 \%$ of the adult population (Morley-Forster, Pergolizzi, Taylor, Axford-Gatley, \& Sellers, 2013). According to the Institute of Medicine (IOM) (2011), approximately one third of the US population is afflicted with chronic pain. A study done by Hoffman, Meier, \& Council (2002) examined the chronic pain rate in a rural population in North Dakota to compare the national averages with that of a rural area. The majority of their participants $(58 \%)$ had experienced or 
was currently experiencing chronic pain, a percentage considerably higher than the national averages previously mentioned.

Osteoarthritis, low back pain, neck pain, and other musculoskeletal disorders are leading causes of disability worldwide and the most common source of chronic pain (Marley et al., 2014). Chronic pain has a significant effect on the lives of its victims, disturbing their ability to work, maintain relationships, and carry out normal daily activities. In addition to being affected by high levels of physical disability, individuals with chronic pain seem to have an amplified risk for developing a variety of comorbid health conditions such as depression, obesity, heart disease, cancer, and early mortality (Andersson, 2009; McBeth et al, 2009).

Chronic pain can be an ongoing condition that leads to a high degree of disability through the loss of autonomy. It is projected in a European Consensus Report (2010) that $25 \%$ of European patients with chronic pain will lose their employment as a direct result of the pain. Consequently, chronic pain is associated with a significant financial burden. Estimating the cost of chronic pain can present challenges as it increases with the intensity of the pain and barriers to care. The IOM reported that the total annual incremental cost of health care due to pain ranged from $\$ 560$ billion to $\$ 635$ billion dollars in the United States (US) in 2010, which combines the medical costs of pain care and the economic costs related to disability days, lost wages, and productivity. The economic burden of chronic noncancerous pain (CNCP) is substantial and increases with the level of pain disability, which suggests the need for and potential benefits of improving CNCP management through specific and adapted treatment plans targeting the impact of pain on daily functioning (Marley et al., 2014). 


\section{Challenges to Enactment of a Pain Management Program}

In the US, trends in the use of opioids for the management of pain have drastically changed over the past 30 years (Atkinson, Schatman, \& Fudin, 2014). Beginning in 2000, an increase in the use of opioids was seen in the management of pain. The high percentage of patients with under treated pain was an impetus for providers and pain societies to lobby for increased use of opioids for all pain types including CNCP. The approval of new standards for pain management incorporating pain as the "fifth vital sign" by the Joint Commission on Accreditation of Healthcare Organizations (JCAHO) seemingly fueled this increase in opioid prescriptions (JCAHO, 2006). As prescriptions for opioid analgesics tripled, opioid overdoses doubled, and accidental overdose deaths associated with opioids increased (Jones, Mack and Paulozzi, 2010). Following the publication of data that confirmed that the risk of addiction associated with chronic opioid use was likely underestimated, guidelines released for the use of controlled substances reflected a change in attitude (Walwyn, Miotto, \& Evans, 2010; Federation of State Medical Boards of the United States, 2005). According to Atkinson and colleagues (2014), at present, there is a universal agreement that opioids are over-prescribed and education among health care providers is profoundly deficient. There is a need for education to focus on a balance between treating legitimate pain patients and mitigating abuse, overdoses, and related deaths. Just as the risk of opioid treatment was underestimated previously, today adverse outcomes or addiction is being used to illegitimately deny access to large groups of patients who struggle daily with chronic pain (Atkinson et al., 2014). In this environment, physicians and nonphysician prescribers, pharmacists, regulatory agencies, and insurers are seeking concrete objectives for mediation. 


\section{Legislative Intervention}

In 2012, the governor of West Virginia signed into law a bill to address the prescription drug diversion and substance abuse related problems in West Virginia (WV). Within this law was the Chronic Pain Licensing Act, which requires all pain management clinics to be licensed by the Department of Human Health and Resources (DHHR). Within this Act, a pain management clinic is defined as:

All privately owned pain management clinics, facilities or offices not otherwise exempted from this article and which meet both of the following criteria: (1) where in any month more than 50 percent of patients are prescribed or dispensed opioids or other controlled substances specified in rules promulgated pursuant to this article for chronic pain resulting from non-malignant conditions; (2) the facility meets any other identifying criteria established by the DHHR Secretary by rule. The operational requirements as denoted by the DHHR are: the clinic must be owned by at least one physician; at designation a physician owner manager must be responsible for the operation of the clinic who has completed a pain medicine fellowship accredited by the Accreditation Council for Continuing Medical Education (ACCME) or be board certified by the American Board of Pain Medicine (ABPM) or American Board of Anesthesiology (ABA) or other board certification approved by the Secretary of the DHHR; the physician owner must practice at the clinic and is responsible for supervising the employees and for complying with all regulations for licensing and operation of the clinic; no owner or employees may have a felony conviction and criminal background checks are mandated; no prescribers who have ever had their Drug Enforcement 
Administration (DEA) number revoked or have had their license to prescribe or dispense controlled substances been denied, or found guilty of a felony for receipt of illicit and diverted drugs may be an owner or employee of a licensed pain clinic; dispensing controlled substances in a licensed pain clinic is allowed only by physicians and pharmacists and only for a 72-hour supply; the treating physician is required to check the controlled substances database on all patients at each examination or at least every 90 days; the pain management clinic shall develop patient protocols, treatment plans and profiles that include the requirement for another physician to evaluate the patient under specific situations; diagnosis and treatment decisions shall be made according to accepted and prevailing standards for medical care; there are requirements for adequate documentation and record keeping; a physical examination is required of the patient on the same day that controlled substances are initially prescribed, dispensed or administered to a patient and at least four times a year thereafter according to accepted and prevailing standards of medical care; the DHHR has authority to perform inspections and revoke licenses of clinics that aren't in compliance and there is a process for the clinic to appeal the decision (West Virginia State Medical Association, 2012, p.1).

However, there is an exemption within the bill that allowed pain management facilities to be excused from registering with the state and meeting the requirements the state demanded under this law.

The practices, clinics and facilities exempted from this regulation are: a facility that is affiliated with an accredited medical school at which training is provided 
for medical or osteopathic students, residents or fellows, podiatrists, dentists, nurses, physician assistants, veterinarians or any affiliated facility to the extent that it participates in the provision of the instruction; a facility that does not prescribe or dispense controlled substances for the treatment of chronic pain; a hospital licensed in this state, a facility located on the campus of a licensed hospital that is owned, operated or controlled by that licensed hospital, and an ambulatory healthcare facility that is owned, operated or controlled by a licensed hospital; a physician practice owned or controlled, in whole or in part, by a licensed hospital or by an entity that owns or controls, in whole or in part, one or more licensed hospitals; a hospice program licensed in this state; a nursing home licensed in this state; an ambulatory surgical facility; and a facility conducting clinical research that may use controlled substances in studies approved by a hospital-based institutional review board or an institutional review board accredited by the Association for the Accreditation of Human Research Protection programs. Any facility that is not included in this section may petition to the secretary for an exemption from the requirements of this article. All such petitions are subject to the administrative procedures requirements of chapter twenty-nine-a of this code (West Virginia State Medical Association, 2012, p.1-2).

Under the exemption, a hospital owned facility, grounded in evidenced-based guidelines with multidisciplinary approaches could provide chronic pain management, a vital service needed, for the vulnerable population in rural WV suffering with $\mathrm{CNCP}$. 


\section{Impact of Legislation in Rural West Virginia}

The WV law had devastating effects on its rural population. Privately owned practices in rural and geographically isolated areas of WV began to stop filling prescriptions and turning away new patients seeking care if they had a diagnosis of chronic pain. These practices exceeded the $50 \%$ regulation and would either have to decrease their prescriptions of narcotics or file for licensure of a pain management clinic. The latter would require a physician owner manager who had completed a pain medicine fellowship accredited by the ACCME or is board certified by the $\mathrm{ABM}$ or ABA or other board certification approved by the Secretary of the DHHR.

The specialty qualifications of providers required by the Chronic Pain Licensing Act to manage a pain center are not often, if ever, found in the rural areas of WV. This is the case in Webster County and its neighboring counties. Private practice physicians in these rural areas once reaching their 50\% mark then began to markedly reduce the number of their chronic pain patients and turned away new patients with the diagnosis of chronic pain. The end result of rural healthcare practices abiding by the Chronic Pain Licensing Act was an influx of chronic pain patients seeking relief with uncontrolled chronic illnesses in the local emergency rooms. The majority of these patients were without a primary care provider (PCP), and claimed they could not be seen at local clinics because they had chronic pain.

\section{A Rural Area of WV}

According to the Health Resources and Services Administration (HRSA), a developed shortage designation criteria was developed to identify whether or not a geographic area, population group or facility is a Health Professional Shortage Area (HPSA) or a Medically Underserved Area or Population (MUAa/Ps). Data on a service area determines a score for that 
area, Index of Medical Underservice (IMU). The IMU scale is from 0 to 100, where 0 represents completely underserved and 100 represents best served or least underserved. Federally Certified Rural Health Clinics (RHCs) is the eligibility for an automatic HPSA designation as having a shortage of health professionals to provide primary, dental, and mental health care services (HRSA, 2014). The rural county of interest is located in the central part of the state in West Virginia with equally rural and geographically isolated neighboring counties. As of the 2010 census, the population for this county was 9,154. The critical access hospital within this rural county has been given an IMU score of 0 designating it as a HPSA and granting it Federally Certified Rural Health Clinic status.

Assuming that chronic pain rates in this rural county of WV were consistent with the national averages, a little over 3,000 people just within the county are afflicted with chronic pain. This presents a significant need for a pain management center.

\section{Rationale for Intervention}

National organizations endorse chronic opioid therapy (COT) along with the use of multidisciplinary approaches for patients with $\mathrm{CNCP}$ as a standard of care in the treatment for their condition [American Pain Society (APS) \& American Academy of Pain Management (AAPM), 2009; American Society of Anesthesiologists (ASA) Task Force on Chronic Pain Management, American Society of Regional Anesthesia (ASRA) and Pain Medicine, 2010]. Implementation of an evidence-based pain management program in rural WV is necessary to improve pain scores, QOL, anxiety, and depression in patients with CNCP. According to Arnstein (2000), both pain intensity and self-efficacy beliefs are consistently important predictors of disability in patients with chronic pain. Arnstein (2000) recommends that therapy 
should be designed to reduce pain intensity and include therapies whose goal is to change thinking and reduce depression and disability associated with chronic pain. Anxiety disorders have also been found to be associated with chronic pain among medical patients in both developed and developing countries (Tsang et al., 2008). These authors recognize a converse angle of approach in that comorbid anxiety and depression should be considered in the assessment of pain. Since chronic pain often accompanies and can increase the duration and severity of mental disorders, mental health professionals should be prepared to address comorbid chronic pain conditions during the treatment of patients with depression and anxiety disorders.

Multidisciplinary approaches to restore self-efficacy were integrated into the pain management center's methodology. Although the pain management center was established March, 2014, the effectiveness of the program on anxiety, depression, quality of life, and pain has not been evaluated.

\section{Problem Statement}

Guidelines recommend COT along with the use of multidisciplinary approaches for patients with CNCP as a standard of care in the treatment for their condition (APS \& AAPM, 2009). A pain management center was established in rural WV in March of 2014 under the guidelines recommend by the APS and AAPM. This capstsone was designed to evaluate the effectiveness of this pain management center while under these guidelines on the outcomes of self-reported depression, anxiety, QOL, and pain. Nine recommended interventions suggested by the APS and the AAPM (2009) were incorporated into the care of 107 adult participants over a six month period. This evaluation of these outcomes will answer whether or not a pain 
management program created under the evidence based guidelines provided by the APS and AAPM can improve anxiety, depression, QOL, and pain over a six month period.

\section{Theoretical Framework}

Self-efficacy, a form of personal control, allows a person specific behaviors necessary to handle a chronic illness (Bandura, 1977). According to Arnstein (2000), both pain intensity and self-efficacy promote the growth of disability and depression in patients with chronic pain. Therefore, the lack of belief in one's own ability to manage pain, cope and function despite persistent pain is a noteworthy catalyst to the degree to which individuals with chronic pain become disabled and/or depressed. The strong impact that high pain intensity has on disability and depression is a comparable stimulus in this scenario (Arnstein, 2000). For these reasons, therapy should target multiple goals including: pain reduction, functional improvement, and the alleviation of depression and anxiety.

\section{Key Elements of Self-efficacy}

Self-efficacy is a person's belief or ability to make the appropriate decisions necessary to implement the needed sequence of activities to achieve a set of goals (Bandura, 1977). Bandura described these beliefs as determinants of how people think, behave, and feel with four major sources of self-efficacy.

Mastery experiences can be used to strengthen one's sense of self-efficacy. This is the most effective way of developing a strong sense of efficacy. Simply put, the achievement of a goal creates mastery experiences and raises self-efficacy. A pain management program that is rooted with clinical guidelines and incorporates multidisciplinary approaches can provide patients with essential tools to set and achieve realistic goals independently. Through a 
multidisciplinary approach using education, professional counseling, medication regimens, and PT programs for functional restoration, individually tailored goals can be set at very obtainable levels.

Social modeling is another important source of self-efficacy. This involves seeing people with similar limitations be successful in developing the capabilities necessary to succeed. Professional counseling has a great advantage in pain management with group therapy sessions. Small groups can meet at the facility for group therapy. Groups can be personalized to gender, marital status, career categories, or even age. This assists in the social modeling aspect of selfefficacy by interacting and learning of the progress in others with chronic pain. It also provides the necessary motivation through support from others with chronic pain.

Social persuasion is verbal encouragement that can be used to enhance one's self efficacy. A pain management program can provide this with monthly conferences with either the professional counselor and/or the registered nurse at each appointment. This serves as a source for verbal encouragement. Positive encouragement increases self-efficacy. Monthly monitoring of the patients' conditions allows for better communication and recognition of any necessary adjustments to prevent a negative experience. Many chronic pain patients have exacerbations of their conditions. This may require adjustments in the patients' treatment plans. A considerable amount of positive encouragement is essential to support the self-efficacy of the chronic pain patient. This can be effectively provided with each medical visit as one or both professional counselors and/or the $\mathrm{RN}$ interact one-on-one with the patient.

The affective process (Bandura, 1977) with the chronic pain patient can be an instinctual reaction to stimulation occurring before the typical cognitive processes can consider the 
formation of a more complex emotion. Negative psychological responses can disturb selfefficacy, however, perception and interpretation of moods, emotional states, physical reactions, and stress levels can improve self-efficacy, if one learns to reframe intense situations. As patients in an evidence-based pain management program begin to reframe the affective process, they come to do the things that they once felt they could never do. For example, as patients with chronic pain may be adjusting well, independently, and developing a higher self-efficacy within their home environments, their higher level of confidence may lead them on an unaccompanied trip to the grocery store outside the home environment. This, in turn, may evoke pain and fear that can markedly alter the self-efficacy. These responses can be shared through the meeting with the professional counselor and/or the $\mathrm{RN}$ at each monthly medical appointment at the management center. Assistance in the interpretation that these are normal psychological responses as opposed to individual incompetence can be reinforced with these visits. It is vital in such situations to provide motivational reinforcement within the affective process to restore levels of self-efficacy. These encounters can also evaluate the individual's psychological responses and emotional states. Coping skills introduced in the educational piece of these encounters can also further support the psychological persuasion of self-efficacy (Bandura, 1977).

Self-efficacy is needed for the management of chronic pain. Because chronic pain can cause debility, fatigue, and exacerbated levels of pain, many patients can develop a lack of confidence in their abilities to do things that might increase pain (Arnstein, 2000). This lack of confidence can be seen as low self-efficacy. Even though these patients may be physically capable of performing certain activities as a result of low self-efficacy, they may refrain from doing them. Self-efficacy then becomes a mediator between chronic pain and unnecessary 
activity restriction. According to Lefort \& Hannah (1994), many patients with chronic pain found when they were actually encouraged to challenge those beliefs and followed through to do so by increasing their activities, the pain did not necessarily increase, and they felt better.

Low self-efficacy arises in chronic pain patients when past experiences in certain situations (e.g. increased pain, fatigue) are generalized to similar activities. Corrective learning occurs through successful accomplishments with various experiences that incorporate verbal persuasion and social modeling. An evidence-based pain management center can provide mastery experiences and social persuasion by lowering pain scores via education with an $\mathrm{RN}$, functional restoration with PT, psychotherapy with professional counseling, and medication regimens with the overseeing physician and NP. Social interaction through the group therapy sessions can stimulate social modeling. This, in turn, can create positive mastery experiences increasing self-efficacy. Higher self-efficacy has been associated with healthier behaviors, such as smoking cessation, and more physical exercise and greater training achievements (Arnstein, 2000). Figure 1 displays the support of a pain management program in the key elements of selfefficacy. 
Figure 1 Key Elements in Self-efficacy

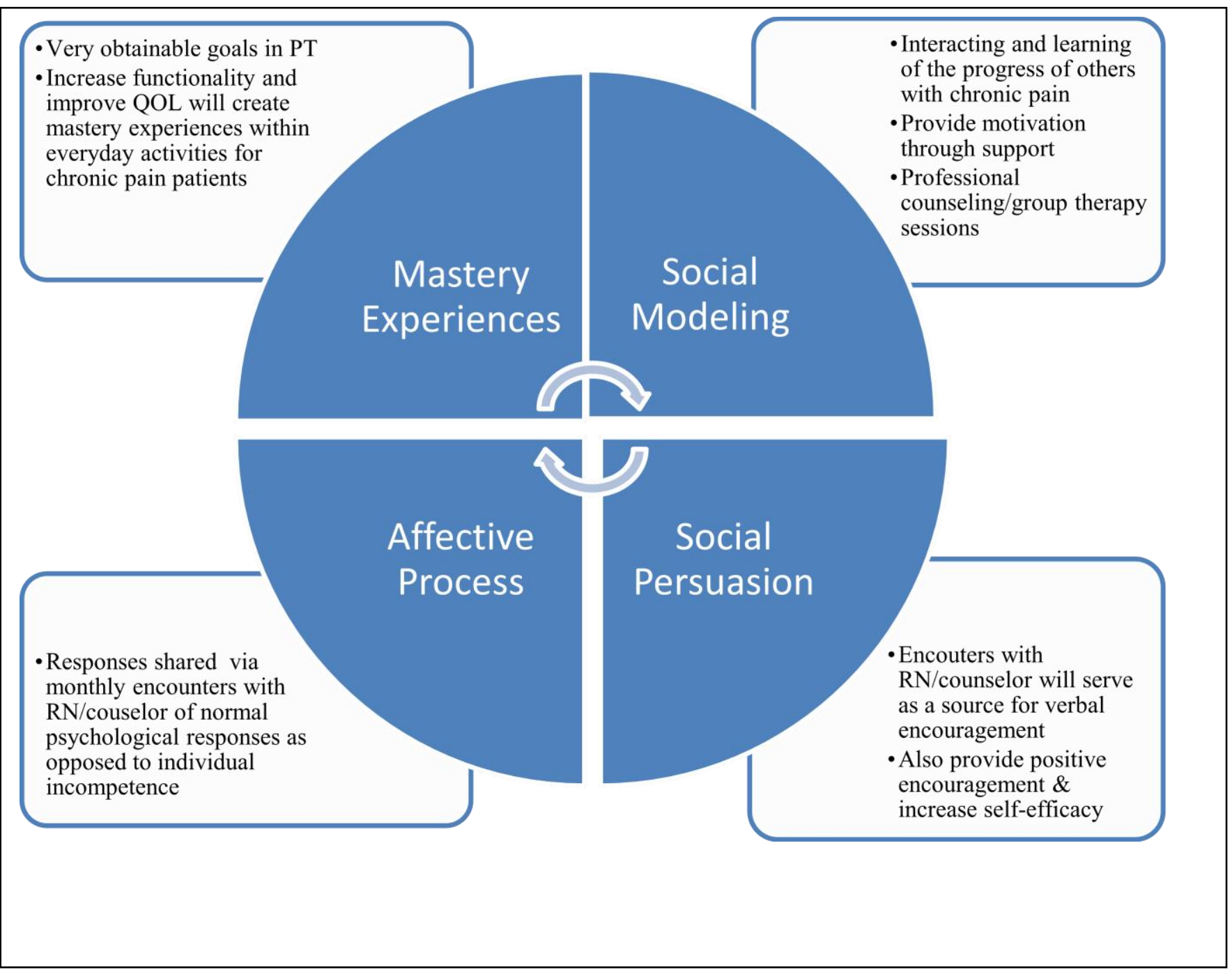




\section{Project Description}

This capstone project was an evaluation of the effectiveness of a pain management program on the outcomes of self-reported anxiety, depression, QOL, and pain. With a multidisciplinary approach grounded in evidence based guidelines, 107 rural adults were assessed pre and post a six month intervention period. The outcomes of self-reported anxiety, depression, QOL, and pain were measured pre and post interventions within one group of participants. Statistical analysis of the collected data was done with Statistical Package for the Social Sciences (SPSS) V22.0. 


\section{CHAPTER II LITERATURE REVIEW}

\section{Literature Review and Synthesis}

The literature review for this project has two sections. The first section was conducted to acquire evidence based guidelines in the management of $\mathrm{CNCP}$ with $\mathrm{COT}$ and multidisciplinary approaches. Findings from this review were used as a guide for the development of a rural pain management center in a rural county in WV. The proposal of this capstone was to examine the effects of the interventions provided under the selected clinical guidelines.

The second section of the literature review examined the effects of the interventions recommended by evidence based guideline on the outcomes of self-reported anxiety, depression, QOL, and pain. This search entails methodical strategies to collect randomized controlled trials (RCTs) and /or systematic reviews (SRs) disseminating the effects of interventions suggested via evidenced based guidelines.

The framework used to guide this literature review was Rosswurm \& Larrabee's (1993) Model for Evidence-Based Practice Change. Specifically, Steps 1, 2 and 3 were completed: assessing the need for a change in practice; locating the best evidence; and, critically analyzing the evidence. Following analysis of the evidence, conclusions about the strength and quality of the evidence are drawn and recommendations for practice are outlined, following Larrabee's instructions for Step 4 of the model: designing a practice change. Larrabee (2009) discussed the levels of evidence hierarchies.

Clinical practice guidelines (CPGs) are systematically developed statements to assist practitioner and patient decisions about appropriate health care for specific 
clinical circumstances. A CPG is a document that represents recommendations for practice based on systematic reviews of available evidence. Usually, a CPG is

developed by a collaborative panel of content experts who prepare evidence tables and rate each recommendation based on strength of the evidence (p. 82-83).

Larrabee suggested searching for a CPG that is relevant to the practice change first. When one is found and the strength rating of the recommendations are strong, the searching for other research reports can be limited thus the time needed for critiquing and synthesizing evidence would be reduced.

\section{Search Strategy for the First Section}

Databases searched for the first section of this proposal included: the National Guidelines Clearinghouse, Cochrane Library, and PubMed. Criteria for inclusion in this review were (1) systematic reviews of clinical guidelines on the management of $\mathrm{CNCP}$ with $\mathrm{COT}$ and multidisciplinary approaches in adults, and (2) clinical guidelines on the management of CNCP with COT and multidisciplinary approaches in adults. Studies were excluded from this review if: (1) they excluded either COT or multidisciplinary approaches such as psychotherapy, PT, education, or adjunct non-opioid methods, (2) they included older adults with impairments, (3) they included children or adolescents, or (4) they were not written in English .

Databases searched for the second section of this proposal included the PubMed and Cochrane Library. Criteria for inclusion in this review were: (1) SR articles relaying the outcomes on self-reported anxiety, depression, quality of life, and pain post the use of any or all interventions suggested by clinical guidelines in the management of CNCP with COT using multidisciplinary approaches in adults, and (2) any RCT studies relaying the outcomes on self- 
reported anxiety, depression, quality of life, and pain post the use of any or all interventions suggested by clinical guidelines in the management of CNCP with COT using multidisciplinary approaches in adults. Studies were excluded from this from this review if: (1) they did not included either COT or multidisciplinary approaches such as psychotherapy, PT, education, or adjunct non-opioid methods, (2) they included older adults with impairments, (3) they included children or adolescents, or (4) they were not written in English .

\section{Study Identification for the First Section}

The keywords "chronic pain", "management", and "adult" were searched within each database for the first section of this literature review, limiting all searches to English language results, but placing limits on publication date to include 2009-2016. Although the keywords were consistent, other limits used in the search varied slightly for each database. Titles and abstracts were evaluated for inclusion criteria. If pain management was indicated in the citation title, the abstract was reviewed for inclusion criteria. Full-text articles were then retrieved and assessed if all inclusion criteria were met. Any article found to meet the study criteria was included.

In the National Guideline Clearinghouse, 345 hits were retrieved. After examination, ten of these met all the inclusion criteria of this review. All of these were guidelines in the management of CNCP with COT. A total of 73 hits were identified in the Cochrane Library. None of these articles met the inclusion criteria. In the PubMed search, 43 hits were produced. After a review of titles, abstracts, and the full texts, there were no systematic review articles meeting criteria for appraisal. 
Ten clinical guidelines on the COT for CNCP were found in the systematic search of this proposal (APS \& AAPM, 2009; ASA Task Force on Chronic Pain Management, ASRA and Pain Medicine, 2010; Washington State Agency Medical Directors' Group, 2010; Management of Opioid Therapy for Chronic Pain Working Group, 2010; Colorado Division of Workers' Compensation, 2011; University of Michigan Health System, 2011; Manchikanti, et al., 2012; Scottish Intercollegiate Guidelines Network (SIGN), 2013; Work Loss Data Institute, 2013; Hooten et al., 2013). Figure 2 illustrates the first section of selecting studies for inclusion in this review (see figure 2). 
Figure 2 First Section Selection of Studies

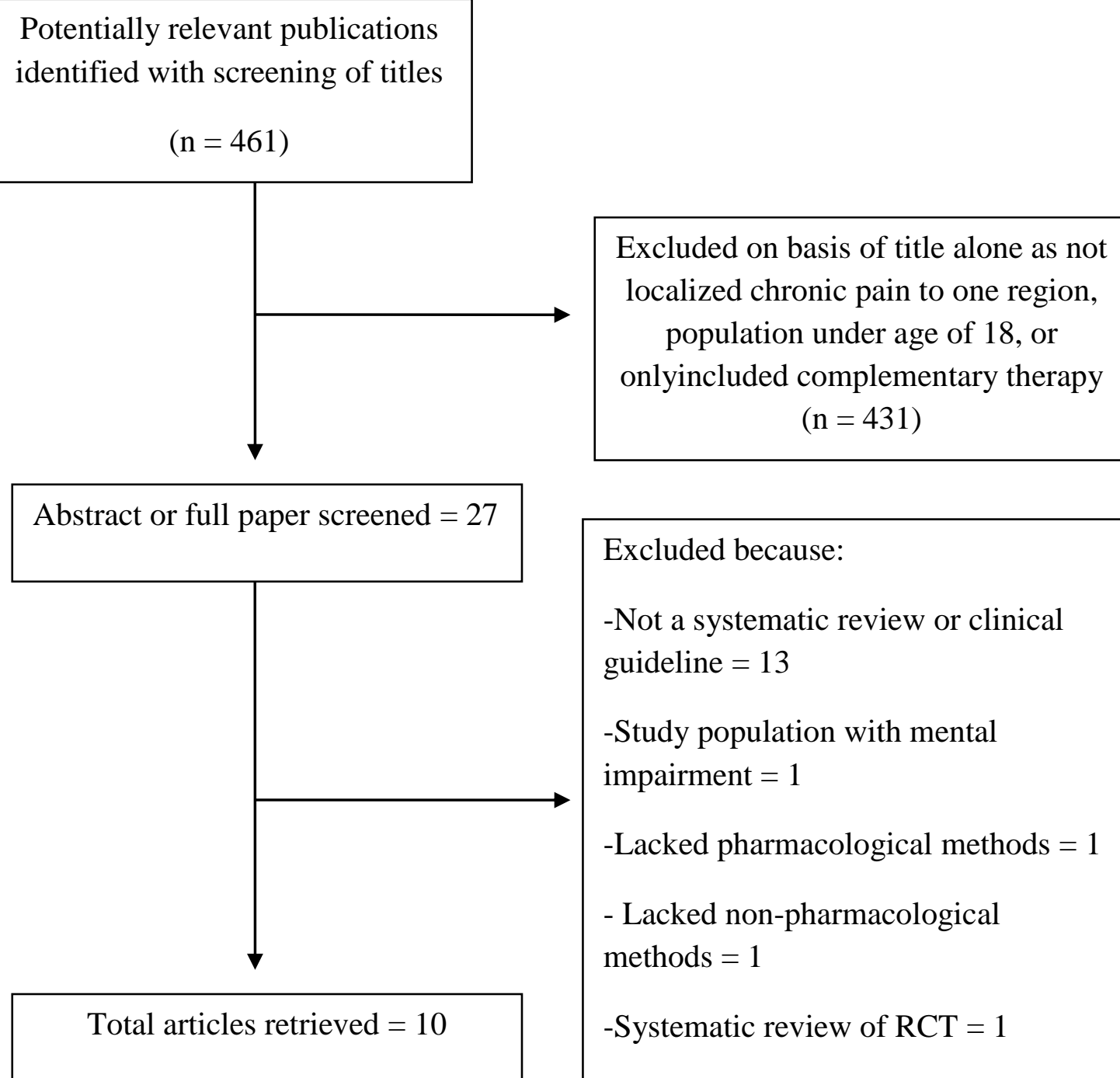




\section{Critical Appraisal Strategies for First Section}

Ten clinical guidelines on the COT for CNCP were found in the systematic search of this proposal (APS \& AAPM, 2009; ASA Task Force on Chronic Pain Management, ASRA and Pain Medicine, 2010; Washington State Agency Medical Directors' Group, 2010; Management of Opioid Therapy for Chronic Pain Working Group, 2010; Colorado Division of Workers' Compensation, 2011; University of Michigan Health System, 2011; Manchikanti, et al., 2012; Scottish Intercollegiate Guidelines Network (SIGN), 2013; Work Loss Data Institute, 2013; Hooten et al., 2013). Table 1 in Appendix A displays the elements of the interventions used by these 10 guidelines included in this review. The clinical guideline with the fewest incorporated interventions was published by Work Loss Data Institute (2013). While it recommended multidisciplinary approaches and specialty consultation, it lacked the components of informed consent, medical monitoring, primary care provider, titration. breakthrough recommendations, and driving safety education. Nevertheless, the clinical guideline published by APS \& AAPM in 2009 included all the interventions listed in Table 1. In order to establish validity, these ten guidelines were assessed using Appraisal of Guidelines for Research and Evaluation II (AGREE II) instrument. AGREE II is the international tool to assess the quality and reporting of practice guidelines (Brouwers et al., 2010).

\section{Quality Assessment of Retrieved Clinical Guideline}

Nuckols and colleagues (2014) assessed with the AGREE II instrument a total of eight out of the ten clinical guidelines selected for this review (APS \& AAPM, 2009; Management of Opioid Therapy for Chronic Pain Working Group, 2010; ASA Task Force on Chronic Pain Management, ASRA and Pain Medicine, 2010; Colorado Division of Workers' Compensation, 2011; University of Michigan Health System, 2011; Manchikanti et al., 2012; Work Loss Data 
Institute, 2013; Hooten et al., 2013). According to Nuckols and colleagues (2014), overall guideline assessment scores were 3.00 to 6.20 (on a scale of 1 to 7 ). Rigor-of-development scores were $20 \%$ to $84 \%$, clarity-of presentation scores ranged from $37 \%$ to $93 \%$, applicability scores were $13 \%$ to $56 \%$, and editorial independence scores ranged from $0 \%$ to $88 \%$.

Most of the appraisers reviewing these eight guidelines for Nuckols and colleagues recommended against using three of these guidelines because of limited confidence in development methods, lack of evidence summaries, or concerns about readability (Colorado Division of Workers' Compensation, 2011; University of Michigan Health System, 2011; ASA Task Force on Chronic Pain Management, ASRA and Pain Medicine, 2010). Nuckols and colleagues found that among the low-to intermediate-quality guidelines (Colorado Division of Workers' Compensation, 2011; University of Michigan Health System, 2011; Management of Opioid Therapy for Chronic Pain Working Group, 2010; Hooten et al., 2013; Manchikanti, et al., 2012; ASA Task Force on Chronic Pain Management, ASRA and Pain Medicine, 2010; Work Loss Data Institute, 2013), shortcomings included limited or no descriptions of input from guideline end users or patients; criteria for selecting evidence, strengths and limitations of evidence, and methods for formulating recommendations; external reviews before publication; plans for updating; barriers to implementation, resource implications, and how to implement guideline recommendations; monitoring and auditing criteria; and measures taken to ensure editorial independence. Nuckols and colleagues found ratings were highest for a guideline by the American Pain Society and the American Academy of Pain Medicine (2009).

The remaining two clinical guidelines, SIGN (2013) and Washington State Agency Medical Directors' Group (2010) were assessed with the AGREE II instrument. The AGREE domain scope and purpose for these guidelines were inversely related as the (mean 3.3) was the 
highest scoring area for Washington State Agency Medical Directors' Group (2010) and the lowest scoring area (mean 2.3) for SIGN (2013). Washington State Agency Medical Directors' Group (2010) had the lowest item score in the AGREE domain of stakeholder involvement with the score of 2.0. The highest AGREE domain scored with SIGN (2013) was in the rigor and development (mean 4.0). With that assessment information, the clinical guideline by the American Pain Society and the American Academy of Pain Medicine (2009) as well as the seven assessed via Nuckols and colleagues were reassessed with the AGREE II. Methodological qualities of all ten clinical guidelines are summarized in Table 2 (Appendix G). Ratings were highest for the guideline by the American Pain Society and the American Academy of Pain Medicine (2009).

\section{Data Abstraction and Process Used}

Qualities assessed via AGREE II along with a characteristic table displaying details from each guideline retrieved in the first section of the literature search facilitated a summary of study characteristics and findings, plus a comparison across all guidelines (Figure 3; Appendix A, Table 1). This supports consistent abstraction of information for all guidelines in this review. Data were extracted detailing particular components recommended as a part of evidence based clinical guidelines in chronic pain management.

\section{Search Strategy for the Second Section}

Four separate searches were performed individually within the database of PubMed and Cochrane Libraries for the second section of this literature review. The first search used the keywords "chronic pain" and "quality of life" for a search within the title without any other limits. From the database, PubMed, 110 hits were retrieved. If either pain management or 
chronic pain with the word "quality of life" was indicated in the citation title, the abstract was reviewed for the inclusion criteria. Full-text articles were then retrieved and assessed if all inclusion criteria were met. Any article found to meet the study criteria was included.

Two articles were selected for review from the 110 hits in PubMed. One RCT study examined the effects of a pain management program utilizing multidisciplinary approaches on the quality of life of 106 participates (Skevington, Carse, \& Williams, 2001). These authors found that quality of life concurrently with depression, anxiety, and pain intensity had significantly improved generally, and in the physical, psychological, and independence domains after one month in a multidisciplinary pain management program. This multidisciplinary program included a consultant anesthetist with specialization in pain management, clinical psychologists, physiotherapists, occupational therapists, and nurses. The types of treatment offered used cognitive behavioral principles and included: education about pain and treatment, changing pain-related behavior, cognitive therapy, exercise and stretch routines to build fitness and flexibility, goal setting, activity scheduling and pacing towards goal attainment, applied relaxation and sleep management, relapse prevention, and maintenance enhancement.

Sixty-six percent of patients included in this study were female and the mean age of the total sample was 44 years (range 22-79 years). The majority, 57\%, was married, $42 \%$ had received post-secondary education, and most $73 \%$ were unemployed. The patients had been in pain for a mean of 8.1 years but duration varied from 15 to 605 months (SD 103). There were significant decreases in mean scores pain measures following treatment (paired $\mathrm{t}$ test). Pain distress was 65.3 before treatment and 55.4 afterwards ( $\mathrm{p}<0.0001 ; 95 \%$ CI: $1.18-1.71$ ), pain intensity changed from 69.1 to 64.1 ( $\mathrm{p}<0.033$; 95\% CI: 1.36 - 1.91), and disruption of activities due to pain from 64.6 to 57.1 ( $\mathrm{p}<0.015 ; 95 \% \mathrm{CI}: 1.21-1.78]$ ). At pretest, self-reported 
depression was assessed. The mean BDI score was 16.6 but with considerable variation (SD 9); this decreased to 11.6 ( $\mathrm{p}<0.0001 ; 95 \%$ CI: 1.25 - 1.82) one month after treatment. Patients showed significant improvement in their overall (general) QOL after treatment, as well. A significant improvement in QOL associated with pain and discomfort was also confirmed following the interventions, thus validating the pain and discomfort facet. Patients with chronic pain also perceived significant improvements ( $\mathrm{p}<0.01$; 95\% CI: 1.18 - 1.75) in their QOL in 9 other facets one month after treatment (Skevington, Carse, \& Williams, 2001). The authors concluded that good QOL was consistently associated with low levels of pain severity and pain distress and little pain disruption of daily life.

The second article included in this literature reviewed was a RCT study that examined data retrieved from 37 inpatients and 36 outpatients with a time elapse of approximately 8 months for inpatients and 7.5 months for outpatients after participating in a pain management program incorporating a multidisciplinary approach treatment regimen lasting 8-12 weeks (Tait, Duckro, Margolis \& Wiener, 1988). Interventions included: behavior therapy, biofeedback training, physical therapy, and medication management. Three areas were measured pre and post interventions, these were health, disability, and psychological status. The authors used the patients' status at the time of follow-up to assess the areas of general health, level of disability, and psychological adjustment. Health status was assessed with a patient pain drawing (PD), a technique that measures pain extent and distribution, and with a symptom index (SI) derived from a nursing protocol. Disability was measured with the Pain Disability Index (PDI), a brief self-report measure of pain-related impairment in seven functional areas. A Role Functioning Inventory (RFI) was developed from the PDI items to assess satisfaction in six of these seven areas plus the patient's optimism for the future. Finally, psychological adjustment was measured 
with three subscales from the Symptom Checklist-90: Depression, Anxiety and Somatization. The Beck Depression Inventory (BDI) was also used to measure depression; the State-Trait Anxiety Index was also used to measure anxiety. These authors compared the standardized measures of in- and outpatient functioning at the time of posttest. MANOVAs revealed inpatients to have more problems with health $(\mathrm{p}<.001)$ and with disability $(\mathrm{p}<.05)$. In the health domain, inpatients reported more widespread pain $(\mathrm{p}<.001)$ and more general symptoms $(\mathrm{p}<.001)$. Inpatients also reported significantly greater disability $(\mathrm{p}<.01)$, although their satisfaction with the quality of life did not differ significantly from outpatients. While there was no significant difference between groups in psychological status, they did differ marginally $(\mathrm{p}<.10)$ across the three variables measuring psychological status. It appeared that there was greater somatization among former inpatients $(\mathrm{p}<.05)$. The pattern of results suggests that, despite more intensive treatment, inpatients reported greater dysfunction on the posttest. The results that are discussed below have been organized into health, disability, and psychological categories. Healthinpatients and outpatients did not differ significantly in the multivariate analysis of the five health variables. While there were significant group differences $(\mathrm{p}<.05)$ on two of the univariate comparisons, frequency of severe pain episodes and daily use of non-narcotic analgesics, these were difficult to interpret in light of the lack of multivariate differences. Outpatients reported improvement on all five variables: improved health $(\mathrm{p}<.001)$, less frequent episodes of severe pain $(\mathrm{p}<.001)$, reduced use of narcotic $(\mathrm{p}<.001)$ and non-narcotic analgesics $(\mathrm{p}<.001)$, and less frequent medical visits $(\mathrm{p}<.01)$. Interestingly, the data suggest that inpatients made significantly greater reductions in daily narcotic use than outpatients $(\mathrm{p}<.05)$. Inpatients reported higher levels of narcotic use than outpatients before treatment and lower levels after treatment. Strong multivariate effects were found for treatment $(\mathrm{p}<.001)$. Multivariate analyses 
showed significant main effects for group $(\mathrm{p}<.01)$ and treatment $(\mathrm{p}<.01)$, as well as a significant group $\mathrm{x}$ treatment interaction $(\mathrm{p}<.05)$. Group differences were especially pronounced in the numbers of hours/day spent lying down $(\mathrm{p}<.001)$, with inpatients reporting more at both pre- and posttest. Outpatients reported sitting for a greater number of hours/day both before and after treatment $(\mathrm{p}<.05)$. While the differences were not significant, outpatients also reported a trend toward standing more than inpatients $(\mathrm{p}<.15)$. Treatment effects were reported by both inand outpatients. There was a significant reduction in time spent reclining daily $(\mathrm{p}<.01)$, although this effect is largely attributable to changes among inpatients; they reduced reclining time significantly more than outpatients $(\mathrm{p}<.01)$. While there was no main effect on hours/day spent sitting, this is because inpatients reported increases in sitting and outpatients reported sitting less, another significant interaction $\mathrm{p}<.05$ ). There were significant changes among patients in both groups in hours/day spent standing $(\mathrm{p}<.01)$, with neither group changing more than the other. Multivariate analyses run on the data collected from the psychological reports showed significant between-group $(\mathrm{p}<.05)$ and treatment-related $(\mathrm{p}<.001)$ differences. Group differences can be attributed largely to more frequent mood changes among inpatients both before and after treatment. Treatment effects are much more powerful, showing less frequent mood changes $(\mathrm{p}<$ $.001)$ and much improved ability to manage pain $(\mathrm{p}<.001)$ among patients in both groups. These authors concluded that both inpatients and outpatients reported positive treatment effects, cutting across health, disability, and psychological dimensions. Both patient groups reported improved functioning across all dimensions approximately eight months following active treatment.

The keywords "chronic pain" and "quality of life" were searched within the title, abstract and keywords without any other limits. In the Cochrane Library, 127 hits were retrieved. If either pain management or chronic pain with the word "quality of life" was indicated in the citation 
title, the abstract was reviewed for the inclusion criteria. Full-text articles were then retrieved and assessed if all inclusion criteria were met. Any article found to meet the study criteria was included.

Two articles were selected for review from the 127 hits in The Cochrane Library. The first article examined is a SR that looked at fifteen RCT studies, which included 5,540 participants and compared opioids against a placebo or other drugs that have been used for low back pain (Chaparro et al, 2013). Most people included in the trials were ages 40 to 50 years, and all reported at least moderate pain across the low-back area. Most of the trials followed the patients during a three month period.

These authors included 15 trials for a total of 5,540 participants. Tramadol was examined in five trials (1378 participants); it was found to be better than placebo for pain (SMD -0.55, 95\% CI: -0.66 to -0.44 ; low quality evidence) and function (SMD $-0.18,95 \%$ CI: -0.29 to -0.07 ; moderate quality evidence). Transdermal buprenorphine (two trials, 653 participants) made little difference for pain (SMD -2.47, 95\%CI: - 2.69 to -2.25 ; very low quality evidence), but no difference compared to placebo for function (SMD -0.14, 95\%CI: -0.53 to 0.25 ; very low quality evidence). Strong opioids (morphine, hydromorphone, oxycodone, oxymorphone, and tapentadol) examined in six trials (1887 participants), were better than placebo for pain (SMD 0.43, $95 \%$ CI: -0.52 to -0.33 ; moderate quality evidence) and function (SMD - $0.26,95 \%$ CI: 0.37 to -0.15 ; moderate quality evidence). One trial (1583 participants) demonstrated that tramadol may make little difference compared to celecoxib (RR 0.82, 95\% CI: 0.76 to 0.90 ; very low quality evidence) for pain relief. Two trials (272 participants) found no difference between opioids and antidepressants for either pain (SMD 0.21, 95\% CI: -0.03 to 0.45; very low quality evidence), or function (SMD -0.11, $95 \%-0.63$ to 0.42 ; very low quality evidence). The included 
trials in this review had high drop-out rates, were of short duration, and had limited interpretability of functional improvement. They did not report any serious adverse effects, risks (addiction or overdose), or complications (sleep apnea, opioid-induced hyperalgesia, hypogonadism). In general, the effect sizes were medium for pain and small for function. Chaparro and colleagues noted that in general, people that received opioids reported more pain relief and had less difficulty performing their daily activities in the short term than those who received a placebo.

The second article examined was a SR that looked at 26 studies with 27 treatment groups that enrolled a total of 4893 participants (Noble et al., 2010). Twenty five of the studies were case series or uncontrolled, long-term trial continuations. The other one was an RCT comparing two opioids. Opioids were administered orally (number of study treatments groups [abbreviated as “ $\mathrm{k}$ "] $=12, \mathrm{n}=3040)$, transdermally $(\mathrm{k}=5, \mathrm{n}=1628)$, or intrathecally $(\mathrm{k}=10, \mathrm{n}=231)$. Many participants discontinued use due to adverse effects (oral: $22.9 \% 95 \%$ CI: $15.3 \%$ to $32.8 \%$; transdermal: $12.1 \% 95 \% \mathrm{CI}: 4.9 \%$ to $27.0 \%$; intrathecal: $8.9 \% 95 \% \mathrm{CI}: 4.0 \%$ to $26.1 \%$ ); or insufficient pain relief (oral: $10.3 \% 95 \% \mathrm{CI}$ : $7.6 \%$ to $13.9 \%$; intrathecal: $7.6 \% 95 \% \mathrm{CI}: 3.7 \%$ to 14.8\%; transdermal: $5.8 \% 95 \%$ CI: $4.2 \%$ to $7.9 \%$ ). Signs of opioid addiction were reported in $0.27 \%$ of participants in the studies that reported that outcome. All three modes of administration were associated with clinically significant reductions in pain, but the amount of pain relief varied among studies.

The authors concluded that the administrations of opioids were associated with clinically significant reductions in pain, but the amount of pain relief varied among studies. According to Noble and colleagues (2010), findings regarding quality of life and functional status were 
inconclusive due to an insufficient quantity of evidence for oral administration studies and inconclusive statistical findings for transdermal and intrathecal administration studies.

The keywords "chronic pain" and "depression" were searched within the title, abstract and keywords without any other limits. The Cochrane Library had 55 hits that were retrieved. If either pain management or chronic pain with the word "depression" was indicated in the citation title, the abstract was reviewed for the inclusion criteria. Full-text articles were then retrieved and assessed if all inclusion criteria were met. Any article found to meet the study criteria was included.

One article was selected for review from the 55 hits in The Cochrane Library (Kamper et al., 2014). The SR evaluated 41 RCTs that compared multidisciplinary treatment to other treatments in patients with chronic low back pain (LBP). Most of the studies compared a multidisciplinary treatment to usual care (general practitioner) or to treatments that only addressed physical factors (such as exercise or physiotherapy). All of the people in the studies had LBP for more than three months, and most had received some other type of treatment previously. Multidisciplinary biopsychosocial rehabilitation (MBR) was defined as an intervention that involves a physical component (for example an exercise program) and at least one other element from the biopsychosocial model, that is psychological or social and occupational. The intervention program had to be delivered by clinicians from different disciplines, with a minimum of two healthcare professionals from different professional backgrounds. Primary outcomes that were measured were pain, functionality, and work status. Some secondary outcomes were QOL, anxiety, depression, and coping strategies. 
These authors reviewed forty-one trials, which included a total of 6,858 participants with a mean duration of pain of more than one year who often had failed previous treatment. Sixteen trials provided moderate quality evidence that multidisciplinary rehabilitation decreased pain (standardized mean difference $0.21,95 \% \mathrm{CI}$ : 0.04 to 0.37 ; equivalent to 0.5 points in a 10 point pain scale) and disability $(0.23,95 \%$ CI: 0.06 to 0.40 ; equivalent to 1.5 points in a 24 point Roland-Morris index) compared with usual care. Nineteen trials provided low quality evidence that multidisciplinary rehabilitation decreased pain (standardized mean difference $0.51,95 \% \mathrm{CI}$ : -0.01 to 1.04$)$ and disability $(0.68,95 \%$ CI: 0.16 to 1.19$)$ compared with physical treatments, but significant statistical heterogeneity across trials was present. Eight trials provided moderate quality evidence that multidisciplinary rehabilitation improves the odds of being at work one year after intervention (odds ratio1.87, $95 \%$ CI: 1.39 to 2.53 ) compared with physical treatments. Seven trials provided moderate quality evidence that multidisciplinary rehabilitation does not improve the odds of being at work (odds ratio $1.04,95 \%$ CI: 0.73 to 1.47 ) compared with usual care. Two trials that compared multidisciplinary rehabilitation with surgery found little difference in outcomes and an increased risk of adverse events with surgery.

Kamper and colleagues concluded that MBR interventions were more effective than usual care (moderate quality evidence) and physical treatments (low quality evidence) in decreasing pain and disability in people with chronic low back pain. Overall these authors found that when compared with usual care, MBR decreased pain and disability to a moderate degree but had little to no effect on work outcomes. When compared with physical rehabilitation, MBR showed moderate effects on pain, disability, and work outcomes. The inconsistent nature of data collection and reporting made drawing conclusions regarding the secondary outcomes of quality of life, healthcare utilization, and adverse events difficult. Comparable estimates for these 
outcomes were reported by too few studies to estimate the effect of MBR. MBR did not appear to have any additional significant effect on symptoms of depression compared to physical rehabilitation (Kamper et al., 2014).

The keywords "chronic pain" and "anxiety" were searched within the title, abstract and keywords without any other limits. From the Cochrane Library, 22 hits were retrieved. If either pain management or chronic pain with the word "anxiety" was indicated in the citation title, the abstract was reviewed for the inclusion criteria. Full-text articles were then retrieved and assessed if all inclusion criteria were met. Any article found to meet the study criteria was included.

One article was selected for review from the 22 hits in The Cochrane Library (Kamper et al., 2014).This article was reviewed previously within the second search and already included in this literature review.

The search among PubMed and The Cochrane Library for the keywords "chronic pain" and "anxiety" yielded 124 hits. Two articles were reviewed (Smeeding, Bradshaw, Kumpfer, Trevithick, \& Stoddard, 2010; Kamper et al., 2014). One article was already included into this literature review (Kamper et al., 2014). Therefore only one article was included in this literature review from the third search (Smeeding, Bradshaw, Kumpfer, Trevithick, \& Stoddard, 2010). This study's purpose was to investigate the effectiveness of the Integrative Health Clinic and Program, an innovative outpatient clinical service that provides nonpharmacologic, biopsychosocial interventions using research based mind-body skills and complementary and alternative therapies. The study assessed improvement in chronic nonmalignant pain and related depression, anxiety, and health-related quality of life. The authors used a retrospective, post-hoc, 
quasi-experimental design with a group analysis comparing chronic non-spinal related pain (CNSP) (e.g., joint pain, headache, and fibromyalgia) $(n=53)$ to chronic spinal-related pain (CSP) (e.g., back pain and neck pain) $(n=88)$. Data were collected at intake and up to four follow-up visits. Hierarchical Linear Modeling was used for statistical analysis. Outcome measures included: Quality of life (Short Form-36), depression (Beck Depression Inventory), and anxiety (Beck Anxiety Inventory).

Smeeding and colleagues found that there were statistically significant differences within and between the CNSP and CSP groups across all follow-up visits. For the CNSP group, depression, anxiety, and bodily pain significantly improved with moderate-to-large effect sizes at 6 months (Cohen's $d=0.74,0.53$, and 0.66, respectively; 95\% CI: -11.2 to-5.8,-9.2 to-4.0, 6.416.2, respectively), and these benefits persisted across all follow-up visits. The CSP group showed an improvement trend in bodily pain (Cohen's d=0.26, 95\% CI: $-0.5-9.0)$. At 6 months, only a small improvement was revealed in the SF-36 subcategory of bodily pain for the CSP group. A trend suggesting declining general health was noted at 6 months (95\% CI: 8.3-0.01), that became significant at 12 months and persisted to 24 months. By 24 months, a significant decline in the SF-36 role emotional and level of depression was noted in the CSP group (95\% CI: -25.9 to-2.1). The between group comparisons revealed significant differences between the CNSP and the CSP groups in all outcome categories. The difference between the pain groups was highly significant $(\mathrm{P}<0.001)$ with a moderate-to-large effect size for both depression (Cohen's d=0.68, 95\% CI: -11.4 to -4.3 ) and anxiety (Cohen's d=0.53, 95\% CI: -10.2 to -3.2 ) with the CNSP group deriving a greater and longer-lasting benefit after participation in IHCP than the CSP group. The between group comparisons for SF-36 subscales were all significant 
$(\mathrm{P}<0.05)$ with effect sizes ranging from moderate for role physical at 0.64 to small for social functioning at 0.38 . The CNSP group derived a significantly greater benefit over time.

The fourth and final search of the second section used the keywords "chronic pain" and "multidisciplinary pain management" within the title only for each database without any other limits. From the database, PubMed, 72 hits were retrieved. If the words "pain management" and "chronic pain" was indicated in the citation title, the abstract was reviewed for the inclusion criteria. Full-text articles were then retrieved and assessed if all inclusion criteria were met. Any article found to meet the study criteria was included.

Two articles were selected to review from the 72 hits within the database, PubMed. The first article, reviewed, was a RCT study that examined the development of general health and physical activity of patients with chronic pain in an interdisciplinary outpatient pain management program (IOPP). Thirty-six patients with an average age of 48 years were included in the IOPP (Joos, Uebelhart, Michel, \& Sprott, 2004). The IOPP consisted of a theoretical section, painting therapy, medical training therapy (MTT), group psychotherapy, relaxation therapy, medical motion therapy and physiotherapeutic, psychotherapeutic and/or medicinal individual therapies adapted to individual patient problematic areas, and one evening with family members. Various questionnaires were completed before and at the end of the program, as well as 3, 6 and 12 months after the completion of the program. They included the SF-36, health-related questionnaire, the Hospital Anxiety Depression Scale (HADS), anxiety and depression questionnaire, the Multidimensional Pain Questionnaire (MPI-D), the Coping Strategy Questionnaire (CSQ), a questionnaire on coping with pain, the model sheet, a sociodemographic and socioeconomic survey, the Goal Attainment Scale (GAS), the examination of goal achievement, and a pain and sleep diary. 
Overall, this study included 36 patients (22 women and 14 men) in the IOPP from the beginning of 1999 until mid-2000. Participants suffered from chronic non-malignant pain and had multiple failed therapies in their history. Occurrence of pain for a duration exceeding six months was considered to be chronic. The patients presented with marked deficiencies in the eight categories of the SF-36 before, as well as after completion of the IOPP. They were particularly impaired with regard to the parameters role-physical [RP] and bodily pain (BP). An alteration of the score values by 6 to 8 points (per dimension) was considered as clinically significant. Such an improvement was only achieved in the functions mental health (MH) and role emotional (RE) components. The average values of the healthy US reference population were never attained in one of the 8 health categories.

In addition, the participants underwent body assessment tests to determine their development in the physical field. These authors concluded that prior to therapy a substantial impairment was found on different levels. Marked improvements in the psychological parameters were obtained by the end of the program ( $\mathrm{MH}$ [pre $46.8 \pm 3.6$, post $53.8 \pm 3.3$, $p=0.043$ ]; RE [pre $35.5 \pm 7.3$, post $48.3 \pm 7.1, p=0.043$ ]; social functioning [pre $40.3 \pm 4.2$, post $42.2 \pm 4.1, p=0.043$ ]; vitality [pre $28.9 \pm 2.5$, post $31.8 \pm 2.7, p=0.043])$. The study found that patients who underwent an interdisciplinary treatment without delay had less pain and a better psychological condition. However, no success was achieved with regard to the physical assessments. Physical functioning (PF) improved after six months by an average of 4 points (clinically non-significant). After the third and the last follow-up period, a marked and clinically significant deterioration far below the starting values was observed. RP remained constantly low over time (Joos, Uebelhart, Michel, \& Sprott, 2004). According to these authors, a major problem encountered with the IOPP was a relatively high rate of premature termination. 
The second article evaluated the effects of a multidisciplinary pain management program on coping, health-related quality of life and pain intensity (Dysvik, Vinsnes, \& Eikeland, 2004). This quasi-experimental design had 76 outpatients suffering from chronic pain complete an eight-week program with therapeutic dialogues and education, combined with physical activity, in order to increase understanding of and attention to non-medical factors that might affect pain perception. The program was active, time-limited, and structured on the basis of multidisciplinary pain management programs based on a cognitive-behavioral approach.

Results of the t-tests, comparing pretest and post-test scores on pain intensity (pre 66, SD 0.6, post 61.6, SD 20.8, $p=0.03$ ) and coping in the domains of problem-focused and emotion focused (pre 1.1, SD 0.4, post 1.2, SD 0.5, $p=0.01$; pre 1.1, SD 0.5, post 1.0, SD 0.5, $p=0.02$, respectively) indicated significant improvements. There was also a significant reduction in pain intensity. As regards SF-36 data, global mental health was improved as well as the subscale scores labeled mental health, vitality, social functioning, physical functioning, and health transition (pre 43.9, SD 11.4, post 46.5, SD 11.4, $p=0.0$; pre 33.7, SD 20.8, post 39.2, SD 20.8, $p=0.02$, pre 52.0, SD 22.5, post 60.8, SD 22.0, $p=0.00$; pre 50.3, SD 24.4, post 55.0, SD 23.1, $p=0.00$, pre 50.4, SD 27.2, post 55.7, SD 29.0, $p=0.05$, respectively). These authors concluded that their findings suggest that this program has the potential to improve coping skills and healthrelated quality of life. Additionally, pain intensity was reduced.

The keywords "chronic pain" and "multidisciplinary pain management" were searched within the title, abstract and keywords without any other limits. From the Cochrane Library, five hits were retrieved. If either pain management or chronic pain was indicated in the citation title, the abstract was reviewed for the inclusion criteria. Full-text articles were then retrieved and 
assessed if all inclusion criteria were met. Any article found to meet the study criteria was included.

One article was selected for review from the five hits in The Cochrane Library (Kamper et al., 2014).This article was reviewed previously within the second search and already included in this literature review.

The second section of this literature search resulted in a total of 727 hits from four phases within two databases, PubMed and The Cochrane Library. Fifteen articles were selected for review. Criteria for inclusion in this review were: (1) SR articles with outcomes of self-reported anxiety, depression, quality of life, and pain post the use of any or all interventions suggested by clinical guidelines in the management of CNCP with COT using multidisciplinary approaches in adults, and (2) any RCT studies with the outcomes of self-reported anxiety, depression, quality of life, and pain post the use of any or all interventions suggested by clinical guidelines in the management of CNCP with COT using multidisciplinary approaches in adults. Studies were excluded from this from this review if: (1) they did not included either COT or multidisciplinary approaches such as psychotherapy, PT, education, adjunct non-opioid methods, (2) they included older adults with impairments, (3) they included children or adolescents, or (4) they were not written in English . Eight were selected for inclusion into the literature review for this proposal (Tait, Duckro, Margolis \& Wiener, 1988; Skevington, Carse, \& Williams, 2001; Joos, Uebelhart, Michel, \& Sprott, 2004; Dysvik, Vinsnes, \& Eikeland, 2004; Noble et al., 2010; Smeeding et al., 2010; Chaparro et al., 2013; Kamper et al., 2014). Figure 3 illustrates the second section process of selecting studies for inclusion in this review (see figure 3). 
Figure 3 Second Section Selection of Studies

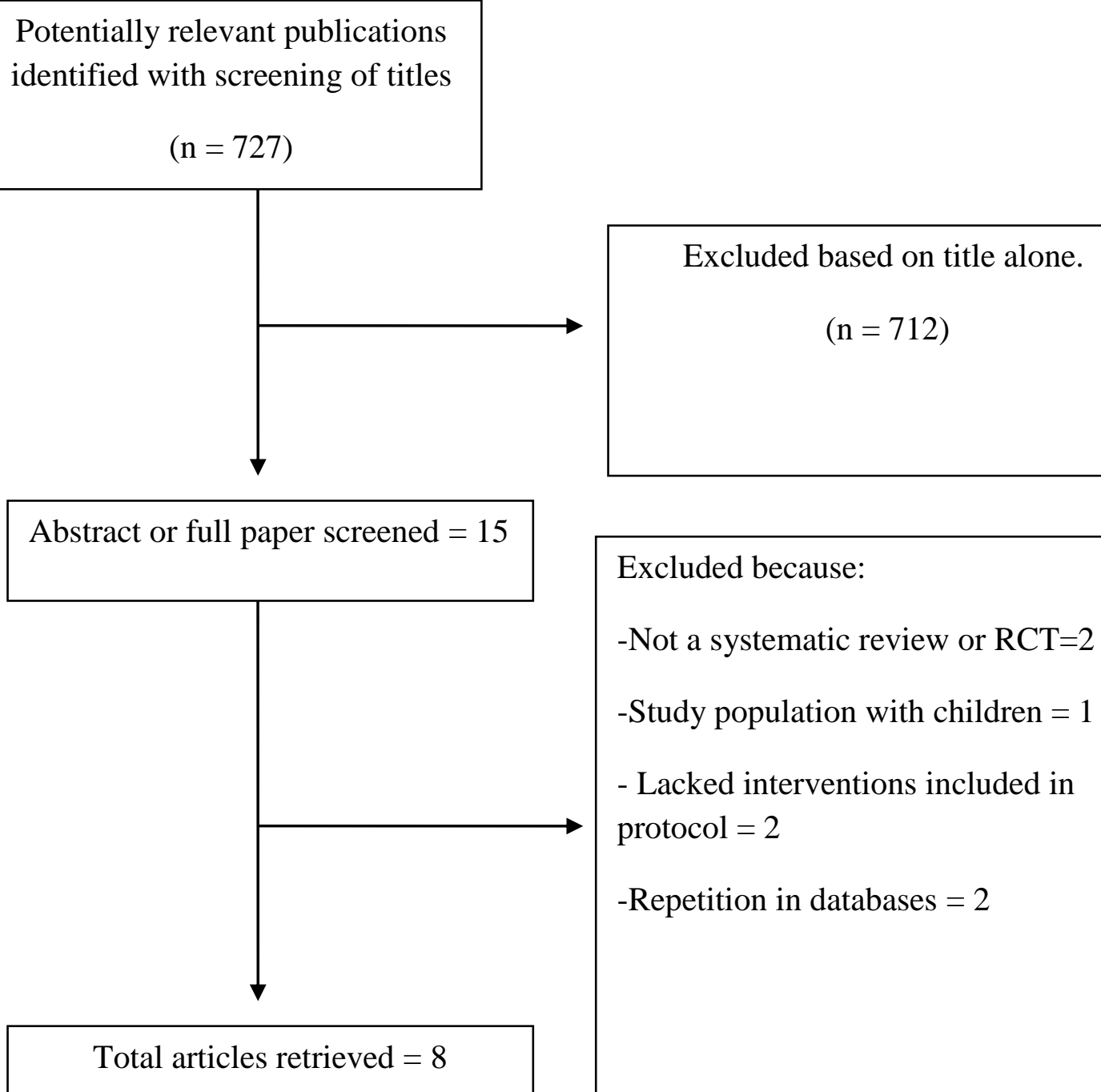




\section{Synthesis}

According to Noble et al. (2010), COT in CNCP can be effective in providing long-term pain relief for some patients. Findings of the review indicated that by incorporating evidence based clinical guidelines that use opioid risk, mitigation strategies along with psychotherapeutic interventions, functional restoration, interdisciplinary therapy, and other adjunctive non-opioid therapies, could aid providers to attenuate the increasing rates of opioid misuse and overdose among patients with $\mathrm{CNCP}$ as well as effectively treating their pain.

The first section of the literature search reviewed ten guidelines. Methodological qualities of all ten clinical guidelines are summarized in Figure 3. Rankings were the highest for the guideline by the American Pain Society and the American Academy of Pain Medicine (2009). Under this evidence based clinical guideline the recommendations for opioid risk, mitigation strategies along with psychotherapeutic interventions, functional restoration, interdisciplinary therapy, and other adjunctive non-opioid therapies could be applied in a chronic pain management center to assess the outcomes of perceived pain, QOL, depression, and anxiety.

The second section of the literature review identified three SRs (Chaparro et al., 2013; Kamper et al., 2014; Noble et al., 2010) and five RCTs (Tait, Duckro, Margolis \& Wiener, 1988; Skevington, Carse, \& Williams, 2001; Joos, Uebelhart, Michel, \& Sprott, 2004; Dysvik, Vinsnes, \& Eikeland, 2004; Smeeding et al., 2010). Two SRs (Chaparro et al., 2013; Noble et al., 2010) looked at the use of narcotics as an intervention for improving pain and functionality in chronic pain. The other six articles (Tait, Duckro, Margolis \& Wiener, 1988; Skevington, Carse, \& Williams, 2001; Joos, Uebelhart, Michel, \& Sprott, 2004; Dysvik, Vinsnes, \& Eikeland, 2004; Smeeding et al., 2010; Kamper et al., 2014) used multidisciplinary interventions to assess outcomes. Five of those six articles looked at the outcome of QOL under multidisciplinary 
interventions (Skevington, Carse, \& Williams, 2001; Joos, Uebelhart, Michel, \& Sprott, 2004; Dysvik, Vinsnes, \& Eikeland, 2004; Smeeding et al., 2010; Kamper et al., 2014). Another five articles looked at the outcome of anxiety and depression under multidisciplinary interventions (Skevington, Carse, \& Williams, 2001; Joos, Uebelhart, Michel, \& Sprott, 2004; Smeeding et al., 2010; Kamper et al., 2014). All six articles look at the outcome of pain under multidisciplinary interventions (Skevington, Carse, \& Williams, 2001; Joos, Uebelhart, Michel, \& Sprott, 2004; Smeeding et al., 2010; Kamper et al., 2014; Dysvik, Vinsnes, \& Eikeland, 2004). The findings in the second section of the literature review demonstrate that multidisciplinary interventions can significantly improve QOL, anxiety, depression, and pain (Skevington, Carse, \& Williams, 2001; Joos, Uebelhart, Michel, \& Sprott, 2004; Smeeding et al., 2010; Kamper et al., 2014; Dysvik, Vinsnes, \& Eikeland, 2004 ). Interventions and outcomes of the second literature search are displayed in Table 3 (Appendix H). 


\section{Assumption}

According to Arnstein, therapy designed to reduce pain intensity and therapies that include goals to change thinking, reduce depression and disability associated with chronic pain improve self-efficacy thereby improving quality of life (2000). Tsang and colleagues found anxiety disorders to be associated with chronic pain (2008). These authors recognize a converse angle of approach in that comorbid anxiety and depression should be considered in the assessment of pain and similarly, since chronic pain often accompanies and can increase the duration and severity of mental disorders, mental health professionals should be prepared to address comorbid chronic pain conditions during the treatment of patients with depression and anxiety disorders.

Based on findings of this review, it was hypothesized that a pain management center in rural WV using COT and opioid risk mitigation stratification along with psychotherapeutic interventions, functional restoration, interdisciplinary therapy, and other adjunctive non-opioid therapies can be an effective therapy for carefully selected and monitored patients with CNCP, and thereby improve pain, quality of life, and depression and/or anxiety.

This practice change was constructed under the guidelines by the American Pain Society and the American Academy of Pain Medicine (2009) and designed to maximize availability of chronic pain management and increase patient access to primary care in rural WV. By providing a subspecialty care of pain management through this practice change, primary care providers can now take more patients into their practices for the management of their chronic illness as these patients are not prescribed narcotics by the primary care provider. This project examined the effectiveness of an implemented practice change, a chronic pain management 
program, on the self-reported pain scores, quality of life, depression, and anxiety of the participants' pre and post a six month intervention period.

\section{Potential Bias}

Two principal sources of potential bias are possible with this review. First, a single reviewer completed the process of identifying and appraising evidence. Use of at least two reviewers is recommended to strengthen reliability of the review process (Schlosser, 2007). Steps taken to minimize the effect of this limitation included the use of a framework to guide the steps of the review, and standardized instruments for appraisal of the evidence. Publication bias is also a potential limitation of this review. The search and appraisal in this review was for only full text published research. Positive findings are more likely than negative or null findings to be published (Schlosser, 2007), therefore the evidence in this review may be an over-estimation of the effect of COT in CNCP on the outcomes of interest.

\section{Congruence of Organizations Strategic to Program}

A critical access hospital with a rural health clinic located in central WV implemented a chronic pain management program with the mission to provide affordable, quality health care to its rural population. This program was grounded upon the APA \& AAPM (2009) clinical guidelines for COT in CNCP. It used multidisciplinary approaches to provide diverse care for its patients. Physical therapy and professional counseling services were located right at the program's center to ease transportation burdens for the rural population. This center also provided TeleMed consultation for specialty consults (e.g. pain interventionist, psychiatry, neurology). One of the objectives of this capstone was to evaluate the effectiveness of this program on the self-reported pain scores of the sample. The second outcome was to evaluate the 
effect of the intervention on the participants' self-reported quality of life. The third outcome was to evaluate the effect of this program on the participants' self-reported depression. Lastly, this capstone project evaluated the effect of this program on the participants' self-reported anxiety. 


\section{CHAPTER III METHODOLOGY}

\section{Program Design}

This capstone project was an evaluation of the effectiveness of a chronic pain management program involving a secondary analysis of a de-identified data set on the outcomes of self-reported pain, QOL, depression, and anxiety. Interventions included multiple components such as: a history \& physical, diagnostic assessments, risk stratification, pain management agreements, informed consent, monitoring, educational pieces, physical therapy, and psychosocial assessment. The outcomes of self-reported pain, QOL, depression, and anxiety were measured pre and post interventions for one hundred and seven participants. The program length was 6 months. A statistical analysis of the collected data was completed using descriptive statistics for the demographics and paired sample t-tests for the selected outcome variables.

\section{Instruments}

The McGill Pain Questionnaire (MPQ) has become one of the most widely used tests for the measurement of pain (Melzack, 1975a). The MPQ is a self-report measure of pain studied with a number of diagnoses. The MPQ assesses both the quality and intensity of subjective pain. The 3 major measures are: (1) the pain rating index (PRI), based on two types of numerical values that can be assigned to each word descriptor, (2) the number of words chosen (NWC); and (3) the present pain intensity (PPI) based on a 1-5 intensity scale.

The MPQ is composed of 78 words, of which respondents choose those that best describe their experience of pain. Words are selected from the following categories: Sensory 1 to 10 (pain descriptors), affective 11 to 15 (affective components of pain), evaluative 16 (evaluation of pain), and miscellaneous 17 to 20 (miscellaneous). Scores are tabulated by summing values 
associated with each word; scores range from 0 (no pain) to 78 (severe pain). Qualitative differences in pain may be reflected in respondent's word choice (Melzack, 1975a). This total represents the PRI.

Chronic pain can have a devastating effect on a patient's quality of life. People with chronic pain experience a much poorer QOL than the general population (Fredheim et al., 2008). For people who live with chronic pain, everyday activities are a struggle. The second outcome that was measured was QOL. The SF-36v2 Health Survey Form consists of thirty-six items. Except for the one single-item of self-evaluated transition (SET) (item 2), the scores of the other thirty-five items are summed into eight multi-item scales, including physical functioning (PF), limitations due to physical health problems [role-physical (RP)], bodily pain (BP), general health $(\mathrm{GH})$, vitality (VT), social functioning (SF), limitations due to emotional health problems [roleemotional (RE)], and mental health (MH). The eight multi-item scales are aggregated into physical component summary (PCS) and mental component summary (MCS). The scoring of two summary components and eight scales was performed by Quality Metric Health Outcomes Scoring Software 4.0 based on norms with a mean of 50 and a standard deviation of 10 . For all scales and summary components, higher scores demonstrate better QOL (Zhou et al., 2013).

The reliability of the eight scales and two summary measures has been estimated using both internal consistency and test-retest methods. With rare exceptions, published reliability statistics have exceeded the minimum standard of 0.70 recommended for measures used in group comparisons in more than 25 studies (Tsai, Bayliss, \& Ware, 1997); most have exceeded 0.80 (McHorney et al., 1994; Ware et al., 1993). Reliability estimates for physical and mental summary scores, which are based on formulas for the reliability of aggregate scores, usually exceed 0.90 (Ware et al., 1993). A review of the first 15 published studies revealed that the 
median reliability coefficients (Cronbach's alpha) for each of the eight scales was equal or greater than 0.80 except for SF, which had a median reliability across studies of 0.76 (Ware et al., 1993). The SF-36v2 Health Survey Form is highly suitable in measuring QOL in CNCP patients (Ellert \& Kurth, 2013). In March of 2014, this instrument had a public domain for use in measuring QOL. In August of 2016 post data collection of this evaluation, it became licensed (Optum, 2016).

Tsang and co-authors (2008) found strong associations between chronic pain and mental disorders (e.g. anxiety, depression). One of the outcomes expected was improvement in any depressive symptomatology. The CES-D is a 20-item scale designed to measure depressive symptoms experienced in the past week. Responses range from 0 to 3: $0=$ Rarely or none of the time (less than 1 day); 1 = Some or a little of the time (1-2 days); $2=$ Occasionally or a moderate amount of the time (3-4 days); and $3=$ Most or all of the time (5-7 days). The CES-D total score is calculated by adding the scores for all 20 items giving a range from 0 to 60 , with the suggested cut-off of 16 as indicative of probable clinical depression. It has proved acceptable to both general and clinical populations. When used in a general sample population, the coefficient alpha was .85, giving the tool a high internal consistency (Radloff, 1977). Hann and co-authors (1999) used the CES-D to measure depressive symptomatology in cancer patients. They found this tool to have good internal consistency, with alpha coefficients $>0.85$ for both groups, as well as adequate test-retest reliability in both groups. Construct validity was demonstrated in two ways, via comparisons between the groups and by comparing the CES-D with measures of fatigue, anxiety, and global mental health functioning. The CES-D was established as a valid and reliable measure of depressive symptomatology in this sample of breast cancer patients. The CES-D has good predictive validity among chronic pain patients as 
well (Geisser, Roth \& Robinson, 1997). This instrument is available at no-cost from a public domain (Fisher, 2009).

The Beck Depression Inventory (BDI), created by Aaron T. Beck, is a 21-question multiple-choice self-report inventory, one of the most widely used psychometric tests for measuring the severity of depression. Internal consistency for the BDI ranges from .73 to .92 with a mean of .86. (Beck, Steer, \& Garbin, 1988). These authors report that the BDI demonstrates high internal consistency, with alpha coefficients of .86 and .81 for psychiatric and non-psychiatric populations respectively. Both the CES-D and BDI were used to measure depression, the third outcome.

The last outcome to be measured was anxiety. The Beck Anxiety Inventory (BAI) consists of twenty-one questions about how the subject has been feeling in the last week, expressed as common symptoms of anxiety (such as numbness and tingling, sweating not due to heat, and fear of the worst happening). It is designed for an age range of 17-80 years old. Each question has the same set of four possible answer choices: NOT AT ALL (0 points); MILDLY: It did not bother me much (1 point); MODERATELY: It was very unpleasant, but I could stand it (2 points); SEVERELY: I could barely stand it (3 points). The BAI has a maximum score of 63 . The minimal level of anxiety ranges between the scores of 0-7. Mild anxiety ranges between the scores of 8-15. Moderate and severe anxiety levels range between the higher scores of 16-25 and 26-63, respectively. According to Beck and colleagues the BAI showed high internal consistency with alpha coefficients of 0.92 (Beck, Epstein, Brown, \& Steer, 1988). The BAI has been shown to be a reliable tool for measuring anxiety in CNCP patients (Davidson, Tripp, Fabrigar, \& Davidson, 2008). This instrument has an online site created by Manchester City Council, a local 
government authority for Manchester, a city and metropolitan borough in Greater Manchester, England (Manchester City Council, 2016).

According to Melzack (1975a), preliminary studies showed that data obtained by allowing a patient to fill out the questionnaire by himself was sometimes unreliable. Patients may fail to read the instructions carefully and miss 3 features in part 2: (1) they may choose more than one item from a word list; (2) they may feel compelled to choose a word from every subclass; and (3) they may fail to describe the pain at that moment in time and use words that describe a pain they had earlier. Therefore, a nurse read the instructions out loud to the patients to ensure that they fully understand the questions and the vocabulary asked.

An association between the scale and rank value methods demonstrates a high correlation in Melzack's study (1975a). This is used to determine the PRI scores for each category. Intercorrelations were higher than 0.9 for all categories. The NWC also correlated highly with the PRI with a value of .97. The PPI correlated significantly with the NWC and the PRI. The coefficients for each PRI indices are: sensory, 0.90; affective. 0.82; evaluative, 0.96; miscellaneous, 0.92; total, 0.94. The MPQ has been shown to be a reliable tool for measuring pain in CNCP patients (Davidson, Tripp, Fabrigar, \& Davidson, 2008).

\section{Project Phases}

\section{Initial Visit}

a. The patient was referred by their PCP. If the patient called and had no PCP, the program staff found one within a week with an appointment with a PCP and then a referral was made. At the initial visit, a history and physical, a diagnostic assessment, order of any additional diagnostic imagining exam and a urine drug 
screen (UDS) was done by the NP. The professional counselor performed a risk stratification assessment with the Drug Abuse Screening Test (DAST). The counselor assessed for depression and anxiety with the CES-D scale, the BDI, and the BAI scale. The RN met with the patient and assessed the patient's pain and his/her QOL with the McGill Pain Questionnaire and the SF36v2,respectively

b. Overseeing Physician Visit

1. Within 2 weeks, the overseeing physician and the NP met with the patient and reviewed the 6 month plan of care. Review of the UDS, DAST score, and diagnostic imagining assisted in deciding if opioid therapy was necessary. A medication regimen was designed at that visit. A pain management agreement was reviewed and signed by patient and provider. Informed consent was reviewed with the patient by the NP. Risk and benefits were discussed as well as optional non-opioid therapy. If anxiety and or depression were present in mild levels and the patient was stable, the professional counselor met every 8 weeks with the patient. In the case of a moderate level of depression and or anxiety, the professional counselor met every month with the patient to evaluate stability. If levels were found to be severe, a specialty consult with psychiatric service was set up for the patient.

\section{Follow up visit \#1}

a. The patient was seen by the NP. A UDS was collected. The WV Board of Pharmacy (BOP) was reviewed. This is a secure site that allows medical providers to review all controlled substances that their patient has filled in the state of WV. This is a monitoring system for excessive prescription by multiple providers, 
which is suggestive of aberrant behavior. A pill count on controlled substances was done. Medications were reviewed. Controlled substances were refilled per the overseeing physician if there were no aberrant behaviors or concerns. These were risk mitigation strategies that were done at each visit. A physical therapy referral was processed. The RN assessed the patient to predict possible opioid abuse with the Screener and Opioid Assessment for Patients with Pain-Revised (SOAPP-R), developed by Bulter and colleagues (2004), and educated the patient on potential risks of driving and or operating machinery while taking narcotics. If the SOAPP$\mathrm{R}$ was high, the patient met with the counselor on follow up visit \#2 for a screening with the Opioid Risk Tool (ORT), developed by Webster and Webster (2005), to estimates risk of opioid-related aberrant behaviors. The patient was offered group therapy in chronic pain management classes offered weekly at the PWRC.

\section{Follow up visit \#2}

a. The patient was seen by the NP. Pain levels were assessed and medication within the NP scope could be adjusted if necessary. If scheduled medications outside the NP scope needed to be adjusted, an overseeing physician's appointment was scheduled within the next two weeks. This was a routine assessment done at each NP visit. Risk mitigation strategies were done with this visit. Controlled substances were refilled per the overseeing physician if there were no aberrant behaviors or concerns. Physical therapy should have been in process. The RN assessed the patient to predict possible current opioid abuse with the Current Opioid Misuse Measure (COMM) tool, developed by Butler and colleagues 
(2007), and educated the patient on potential risks of young children getting into their medication, safe storage, and poison control hotline information was given.

IV. Follow up visit \#3

a. The patient was seen by the NP for routine assessment. Risk mitigation strategies were done with this visit. Controlled substances were refilled per the overseeing physician if there was no aberrant behaviors or concerns. Physical therapy should have been completed. Precertification for third party payer's approval of any necessary advanced imagining or diagnostic testing (e.g. electromyography, magnetic resonance imaging) were processed. The RN scheduled approved imaging/testing. The RN assessed the patient with the Pain Assessment and Documentation Tool (PADT) developed by Passik and colleagues (2002) to measure the severity of pain, adverse side effect of the narcotic, and functional improvement. The NP finished the tool by reviewing the RN's intake and going over potential aberrant drug-related behavior and assessment. As part of the RN educational support piece, sleep hygiene and regulating circadian rhythm were discussed with the patient.

V. Follow up visit \#4

a. The patient was seen by the NP for routine assessment. Risk mitigation strategies were done with this visit. Controlled substances were refilled per the overseeing physician if there was no aberrant behaviors or concerns. Physical therapy should have been completed. Review of advanced imaging/testing and specialty consultation referral was processed. The RN assessed the patient with the Brief Pain Inventory (BPI) developed by Cleeland (1989) to measure the 
severity of pain and educated the patient on calories reduction and low impact exercise.

VI. Follow up visit \#5

a. The patient was seen by the NP for routine assessment. Risk mitigation strategies were done with this visit. Controlled substances were refilled per the overseeing physician if there was no aberrant behaviors or concerns. Physical therapy should have been completed. Pain specialty consult should have been completed and interventions scheduled. The RN assessed the patient with the PADT, once again, to measure the severity of pain, adverse side effect of the narcotic, and functionality improvement. The NP finished the tool by reviewing the RN's intake and going over potential aberrant drug-related behavior and assessment. The RN offered education to nonsmokers on second hand smoke. For those patients that were smokers, the professional counselor met with each patient and offered smoking cessation.

V. Care Plan Reassessment

a. At this point, approximately six months had passed. The patients should have had multidisciplinary approaches in their care. They should have had physical therapy, professional counseling, educational support with a $\mathrm{RN}$, an established medication regimen via NP and overseeing physician, primary care for chronic illnesses via PCP, and pain specialty consultations. At the care plan reassessment visit, a history and physical, a diagnostic assessment, review of diagnostic imagining and risk stratification classification was given based on intake over last 6 months. If the patients SOAPP-R, ORT, COMM were of low risk and all their 
UDSs, BOPs, and pill counts revealed no concerns for aberrant behavior over the last 6 months, the patients, in their next 6 month plan of care, would have been classified as low risk and UDS done at follow ups \#2 and \# 5 only. Moderate risk patients continued with monthly UDS. The professional counselor performed a risk stratification assessment with the DAST. The counselor also assessed for depression and anxiety with the CES-D and BDI scales and the BAI, respectively. The RN met with the patient and assessed the patient's pain and his or her QOL with the McGill Pain Questionnaire and the SF-36v2, respectively. Scores were then compared and a new plan of care written. The patient, the NP and the overseeing physician then met in 2 weeks to complete the next 6 month plan.

\section{Project Objectives}

Measurable outcomes within this project were identified in the areas of pain, quality of life, depression, and anxiety. The following outcomes were measured to evaluate the program's effectiveness:

1. Determine the effectiveness of the program on increasing the patient's perception of his or her QOL based upon a change from the pre to post program assessment using the SF-36v2. Two sets of scores comprised the QOL, mental component score (MCS) and physical component score (PCS).

2. Determine the effectiveness of the program on decreasing the patient's perception of his or her anxiety based upon a change from the pre to post program assessment using the BAI. 
3. Determine the effectiveness of the program on decreasing the patient's perception of his or her depressive symptoms based upon a change from the pre to post program assessment using the CES-D scale and the BDI.

4. Determine the effectiveness of the program on decreasing the patient's perception of pain based upon a change from the pre to post program assessment using the McGill Pain Scale.

\section{Evaluation}

The critical access hospital has implemented a program to deliver chronic pain management services to a rural and vulnerable population under the clinical practice guidelines of the APS \& AAPM (2009). The goal of this project was to evaluate the effectiveness of that program to determine if a pain management center treating rural adults with chronic pain integrating evidence based guidelines and multidisciplinary approaches can improve self reported pain scores, QOL, depression, and anxiety using a paired t test. The MPQ, SF-36v2, BDI and CES-D, and BAI were administered at the beginning of the program to assess pain scores, QOL, depression, and anxiety, respectively. The same tools were then used to reassess the same areas 6 months post entering the program. The sample size was one hundred and seven patients. 


\section{CHAPTER IV RESULTS}

\section{Patient Demographics}

All de-identified data were collected from the first 107 participants of the program that completed 3 of the 5 interventions. Analyses were conducted on SPSS for Windows version 10. Frequencies were used to present demographics among the sample. Mean scores across all variables were computed into percentage scores (i.e., scores out of 100) for comparability. A series of paired t-test were used to measure the projects objectives, one through four.

Among the 107 participants, females comprised $56.1 \%$ of the group with the male sample percentage being $43.9 \%$. The mean age for the sample was 53.76 years of age (SD $11.579)$ with a range from 29-86 years. Due to the extreme rural and geographical isolation of the facility's setting, the entire sample was Caucasian. The race reflected the composition of the community. Unemployment percentages among the sample were high at $93 \%$. This may have been a reflection of the poor economy of the area as well as the disability caused by chronic pain. The majority of the sample was single (i.e., divorced, widowed, or never married) and comprised $51 \%$ of the group, while the other $49 \%$ were married at the time of participation.

At the initial assessment of the participants, 96\% suffered with nociceptive pain and $95 \%$ neuropathic pain. Overall, the majority of the sample reported both nociceptive and neuropathic pain characteristics. Upon entering the program, $85 \%$ of the sample did not have a previous pain specialty consult nor had they received any pain specialty interventions (i.e., trigger point injections, facet injection, epidurals, and nerve blocks). Only $36 \%$ of the sample entered the program on some form of scheduled narcotic for pain control. In some states tramadol, butabital, acetaminophen with codeine, and pentazocine are not scheduled drugs. However in the state of 
WV, these are controlled substances and were considered as such for this capstone. The other $64 \%$ of the sample were not receiving any scheduled narcotics per WV Controlled Substance Act for their pain. Upon entering the program, $96 \%$ of the sample received a prescription for a controlled narcotic or a long acting narcotic was added to their current regimen. The remaining $4 \%$ of the group continued with their current regimen. The entire sample had some form of a controlled narcotic for their pain. During the program, $65 \%$ of the participants had some change to their narcotic regimen (i.e., increased quantity, changed to different opioid, long acting added). The remaining 35\% completed the program with the original narcotic prescribed at the beginning of the program.

A mental health assessment was a key component of this multidisciplinary approach. Of the sample, $6 \%$ had already received a pre-program mental health assessment and were under the care of psychiatric services. This may be an outcome reflective of the community's shortage of psychiatric services. The other $94 \%$ had no previous professional consultation with psychiatric services. However, $21 \%$ of the sample were on medications for anxiety, and $11 \%$ were on an antidepressant prior to entering the program as prescribed by their primary care provider. During the program, $100 \%$ of the participants received a mental health assessment with additional counseling if needed. The mental health assessment at the beginning of the program revealed that $57 \%$ of the sample were found to need an agent for their anxiety and were given a prescription. Throughout the program, $43 \%$ received either an increase or a change to a different medication for better control. Benzodiazepines were not prescribed through the program to treat anxiety for any participant. Medication prescribing approaches were at lower doses initially to monitor responses, hence the high percentage of change as they were increased as tolerated during the 
program. These medications included buspirone, sertraline, venlafaxine, duloxetine, and fluoxetine.

Depression was equally considered in the mental health assessment. The mental health assessment at the beginning of the program revealed that $56 \%$ of the sample was found to need an antidepressant agent for their depression and was given a prescription. Throughout the program, $38 \%$ received either an increase or a change to a different antidepressant. Antidepressant prescribing approaches took the same approaches and were implemented at lower doses initially to monitor responses, hence the high percentage of change as they were increased as tolerated during the program. In some case anxiety and depression were both diagnosed in the participants. In these particular incidences, medications treating both anxiety and depression were used as opposed to two separate agents.

Interventions consisted of 5 multidisciplinary approaches. Participants had to complete 3 of the 5 intervention to be included in the sample. One of the interventions was physical therapy. Ninety- three percent of the sample completed physical therapy during the program. Another intervention was individual education at each visit via the registered nurse, which included: diet and exercise, safety of medications and storage, osteoarthritis verse rheumatoid arthritis, physiological mechanism of degenerative disc disease and disc herniation, sleep hygiene, constipation, smoking cessation and second hand smoke exposure, and driving safety. One hundred percent of sample participated in this intervention. The sample also participated in the mental health assessment intervention at $100 \%$. Another intervention offered that coincided with the mental health intervention was psychological counseling. Of the sample, $59 \%$ completed the intervention of psychological counseling during the program. The last intervention offered was pain specialty consult. Of the sample, $32 \%$ received pain specialty consultation. Seven 
participants had life changing events occur during the program (i.e., divorce, death of a spouse, house fire, death of a parent, major hospitalization). However, they completed the interventions and were included in the sample

\section{Associations between Intervention and Outcomes}

Across all outcomes measures, paired sample t-tests were calculated to evaluate whether there were any differences pre- and post-program.

The McGill Pain Questionnaire was administered to assess participants' perceptions of their pain. There was a statistically significant decrease in pain scores from pre-program $(M=36.21 ; S D=11.78)$ to post program scoring $(M=29.24 ; S D=10.74)$. The mean decrease in pain scores was 6.96 with a $95 \% \mathrm{CI}=4.6$ to $9.25 ; t(106)=1.65, p<.05$. The eta squared statistic (0.29) indicated a large effect size thereby validating a vital difference in the pain scores obtained before and after the interventions.

The SF36v2 scale was administered to assess participants' perceptions of their QOL in the Mental Component Score (MCS) and Physical Component Score (PCS). There was a statistically significant increase in MCS scores from pre-program scoring $(M=41.71 ; S D=14.50)$ to post program scoring $(M=49.87 ; S D=12.08)$. The mean increase in MCS scores was -8.13 with a $95 \% \mathrm{CI}=-10.62$ to $-5.70 ; t(106)=1.65, p<.05 .$. The eta squared statistic $(-0.29)$ indicated a large effect size. Likewise, there was a statistically significant increase in PCS scores from preprogram scoring $(M=24.83 ; S D=8.92)$ to post program scoring $(M=28.13 ; S D=10.71)$. The mean increase in PCS scores was -3.29 with a $95 \% \mathrm{CI}=-5.00$ to $-1.58 ; t(106)=1.65, p<.05$. The eta squared statistic (-0.16) indicated a large effect size. These two results demonstrated significant 
improvement in the QOL scores in the mental as well as the physical aspects obtained before and after the interventions.

Participants also completed the Beck Depression Inventory (BDI) and the Center for Epidemiologic Studies Depression Scale (CES-D) to assess participants' perceptions of their depression. There was a statistically significant difference in BDI scores $(t(106)=1.65, p<.05$, $95 \% \mathrm{CI}=1.73$ to 4.39$)$ from pre-program $(M=12.51 ; S D=8.80)$ to post program $(M=9.45$; $S D=8.137)$. The eta squared statistic (0.18) indicated a large effect size. Likewise, there was a statistically significant decrease in CES-D scores $(t(106)=1.65, p<.05,95 \% \mathrm{CI}=4.53$ to 7.97$)$ from pre-intervention $(M=16.43 ; S D=10.82)$ to post program $(M=10.17 ; S D=8.80)$. The eta squared statistic (0.30) indicated a large effect size as well.

Participants completed the Beck Anxiety Index (BAI to assess participants' perceptions of their anxiety. Results revealed a significant decrease in BDI scores at 6.103 with a $95 \% \mathrm{CI}=$ 4.24 to $7.96, t(106)=1.65, p<.05$. The eta squared statistic $(0.30)$ indicated a large effect size with a substantial difference in the anxiety scores obtained from before to after the interventions.

The relationship between the preprogram BDI and BAI scores also demonstrated a strong positive correlation, $\mathrm{r}=.79, \mathrm{n}=107, p<.001$ with a $95 \%$ confidence level ranging from 0.707 to 0.852. There was a significant correlation between the scores post program scores as well, $\mathrm{r}=.63$, $\mathrm{n}=107, p<.001$ with a $95 \% \mathrm{CI}=0.5$ to 0.732 .

There was a positive correlation found between the CES-D and BDI outcomes There was a strong positive correlation between the two variables, $\mathrm{r}=.84, \mathrm{n}=107, p<.001$ with a $95 \% \mathrm{CI}=$ 0.835 to 0.919 . There was also a significant correlation between the scores post program, $r=.66$, $\mathrm{n}=107, p<.001$ with a $95 \% \mathrm{CI}=0.549$ to 0.762 . 


\section{CHAPTER V DISCUSSION, RECOMMENDATIONS, AND CONCLUSION}

This program started in March of 2014, and by December 2015, there was a total enrollment of 863 patients and over 200 referrals waiting to be processed. The primary goal of this project was to evaluate the program's effectiveness in reducing perceived pain, anxiety, and depression as well as the successfulness of increasing QOL in CNCP among the first 107 enrolled participants.

\section{Discussion}

Chronic pain impacts people's well-being, their capacity to sustain an independent lifestyle, productivity, and social relationships (Breivik et al., 2006). Predictably, depression and anxiety disorders have been found to be associated with chronic pain among medical patients in both developed and developing countries (Lepine \& Briley, 2004). National organizations recommend chronic opioid therapy (COT) along with the use of multidisciplinary approaches for patients with $\mathrm{CNCP}$ as a standard of care in the treatment for their condition [American Pain Society (APS) \& American Academy of Pain Management (AAPM), 2009; American Society of Anesthesiologists (ASA) Task Force on Chronic Pain Management, American Society of Regional Anesthesia (ASRA) and Pain Medicine, 2010].

Two articles from the literature examined narcotics and their effects on pain and function (Chaparro et al, 2013; Noble et al., 2010). The use of narcotics was found to be better than placebo for pain and function. In one of the RCTs in the review, the study had a high drop-out rate among the stronger class of narcotics and had limited interpretability of functional improvement. However there was no report of any serious adverse effects, risks (addiction or overdose), or complications (sleep apnea, opioid-induced hyperalgesia, hypogonadism) 
(Chaparro et al, 2013). The investigators noted that in general, people that received opioids reported more pain relief and had less difficulty performing their daily activities in the short term than those who received a placebo.

Noble and colleagues (2010) reviewed opioids that were administered orally, transdermally, or intrathecally. Many participants discontinued use of the drugs due to adverse effects. Signs of opioid addiction were reported in $0.27 \%$ of participants in the studies that reported that outcome. All three modes of administration were associated with clinically significant reductions in pain, but the amount of pain relief varied among studies. The authors concluded that the administration of opioids were associated with clinically significant reductions in pain, but the amount of pain relief varied among studies.

There is a worldwide agreement that opioids are over-prescribed and education among health care providers is extremely deficient (Atkinson et al., 2014), despite this, the rural chronic pain management center being evaluated combines this intervention with other multidisciplinary approaches to treat CNCP. The clinic followed evidence based guidelines set out by APS \& AAPM (2009) in the application of narcotics and integrated stringent risk mitigation strategies.

\section{Intervention Implementation: Evaluation of Effectiveness}

Five articles found in the literature review used multidisciplinary approaches to evaluate QOL in patients with chronic pain (Skevington, Carse, \& Williams, 2001; Kamper et al., 2014; Smeeding et al., 2010; Joos et al., 2004; Dysvik et al., 2004). Skevington, Carse, \& Williams (2001) reinforced that quality of life had significantly improved in the physical, psychological, and independence domains after one month in a multidisciplinary pain management program. 
Their multidisciplinary program included: a consultant anesthetist with specialization in pain management, clinical psychologists, physiotherapists, occupational therapists, and nurses.

Kamper and colleagues (2014) compared multidisciplinary treatment to other treatments in patients with LBP. Multidisciplinary biopsychosocial rehabilitation (MBR) was defined as the intervention used with at least one other element from the biopsychosocial model that is psychological or social and occupational. These authors concluded that there was inconsistency of data collection and reporting, which made drawing conclusions regarding the secondary outcomes of QOL difficult. As a result, comparable estimates for these outcomes were reported by too few studies to estimate the effect of MBR (Kamper et al., 2014).

Smeeding and colleagues (2010) investigated the effectiveness of the Integrative Health Clinic and Program, an innovative outpatient clinical service that provides interventions using research based mind-body skills and complementary and alternative therapies on health-related quality of life. Data were collected using Quality of Life (Short Form-36). Smeeding and colleagues found that there were statistically significant differences within and between the Chronic Non-spinal related Pain (CNSP) and Chronic Spinal Pain (CSP) groups across all follow-up visits in QOL.

Joos and colleagues (2004) used interventions that consisted of a theoretical section, painting therapy, medical training therapy (MTT), group psychotherapy, relaxation therapy, medical motion therapy, and physiotherapeutic, psychotherapeutic and/or medicinal individual therapies. In the area of QOL, an improvement was only achieved in the functions mental health $(\mathrm{MH})$ and role emotional (RE). These authors reported that the average values of the healthy US reference population were never attained in one of the 8 health categories. Some areas within the 
health related QOL showed improvement, however due to a relatively high rate of attrition, these authors were unable to properly assess the success of these interventions.

Another article evaluated the effects of a multidisciplinary pain management program on health-related quality of life (Dysvik, Vinsnes, \& Eikeland, 2004). This study used therapeutic dialogues and education, combined with physical activity, to increase understanding of and attention to non-medical factors that might affect pain perception as an intervention. The program was based upon other multidisciplinary pain management programs with cognitivebehavioral approaches. Global mental health was improved as well as the subscale scores labeled mental health, vitality, social functioning, physical functioning and health transition.

These articles used similar alternative interventions also seen within the program being evaluated for its effectiveness. The improvement in QOL correlates with the effectiveness of the program.

Four of the literature review articles that looked at QOL also looked at anxiety and depression post their multidisciplinary interventions (Skevington, Carse, \& Williams, 2001; Kamper et al., 2014; Smeeding et al., 2010; Joos et al., 2004). Joos and co-authors reported marked improvements in the psychological parameters by the end of the program despite their low retention level. Smeeding and colleagues established that there were statistically significant improvement in depression and anxiety with moderate-to-large effect sizes at 6 months post their interventions. Kamper and colleagues found little to no effect on depression and anxiety post interventions. As with the Smeeding study, the intervention used in this study was clearly effective in decreasing depression and anxiety. 
Another study also looked at the outcome of anxiety and depression post multidisciplinary interventions but did not consider the outcome of QOL (Tait et al., 1988). These authors used a pain management program incorporating a multidisciplinary approach treatment and interventions similar to the program being evaluated. These authors concluded that both inpatients and outpatients reported positive treatment effects, cutting across health, disability, and psychological dimensions. Both patient groups reported improved functioning across all dimensions approximately eight months following active treatment. These findings were congruent with the current study.

These articles were productive in improving anxiety and depression with multidisciplinary approaches also seen within the program being evaluated for its effectiveness. The improvement in these areas correlates with the effectiveness of the program.

All six of the studies using multidisciplinary approaches evaluated the outcome of pain pre and post interventions (Skevington, Carse, \& Williams, 2001; Kamper et al., 2014; Smeeding et al., 2010; Joos et al., 2004; Tait el al., 1988; Dysvik et al, 2004). Regardless of retention factors all articles demonstrated improvement in pain indexes. This study was consistent with the others in demonstrating improvement in pain after the intervention. These articles related to the effectiveness of the multidisciplinary approaches also seen within the program being evaluated as it too improved pain scores.

\section{Key Facilitators and Barriers}

Primary barriers for all patients in rural WV are transportation and financial means. Monthly visits were demanding for most patients. With the assistance of WV transportation vouchers patients receiving them were more likely to keep appointments as scheduled. The 
facility assisted patients in the coordination of their monthly appointments with neighbors or other family members to reduce travel and economical stressors.

The center also incorporated a physical therapy department so patients could attend their therapy sessions occasionally on the same days that their appointment was scheduled for CNCP management. This assisted, again, with compliance and alleviated barriers.

Because this model is the first of its kind and the need is so great, the large volume of patients is due to referrals from outside the rural community in which it is located. At this point, additional staff and exams rooms as well as treatment rooms are needed. Travel and financial burden are taking a toll on these patients traveling to the facility for care under this program, because there is no access to one of this magnitude in their areas. The application of this project in other rural settings in WV under non-profit hospitals could serve as a place for evidence based CNCP management for the underserved. With the continued application of this model throughout the state, there is a potential for marked reduction in the abuse of prescription pain medication, a decline of overdose and addiction rates, an improvement in self-reported anxiety, depression, QOL and pain among CNCP patients. In addition, the model has the potential to improve functionality and decrease debility among CNCP patients, and reduce emergency room use for chronic pain treatment and the management of other chronic illnesses. By this means, this model has the potential to lower healthcare costs and improve the overall state of health of the CNCP patients of WV.

\section{Feasibility of Program Sustainability}

Since completion of the data analyses of the first 107 participants, the program has enrolled 863 patients. Most of the first 107 participants have gone on and completed a second 
program phase that included post testing of anxiety, depression, QOL, pain and an added functionality assessment. Widespread distribution of the programs effects has reached outside communities. The patient population has now gained some diversity in ethnicity.

\section{Conveyance of the Theoretical Framework}

Self-efficacy, as a form of personal control allowing a person specific behaviors necessary to handle a chronic illness (Bandura, 1977) was crucial and unparalleled to any other theory as it related to multiples factors in this capstone. According to Arnstein (2000), both pain intensity and self-efficacy promote the growth of disability and depression in patients with chronic pain. Therefore, the lack of belief in one's own ability to manage pain, cope and function despite persistent pain is a noteworthy catalyst to the degree to which individuals with chronic pain become disabled. For this reason, therapy targeting multiple goals, including: pain reduction, functional improvement, the alleviation of depression and anxiety as well as improving QOL was essential under the key elements of self-efficacy.

An unexpected example outside of the capstones paradigm of self-efficacy was seen in physical therapy. Mastery experiences, key element, can be used to strengthen one's sense of self-efficacy. This is the most effective way of developing a strong sense of efficacy. Simply put, the achievement of a goal creates mastery experiences and raises self-efficacy. However, the program had patients drop out of their physical therapy sessions because it was too aggressive for their debilitated state, and they lacked the belief in their own ability to complete it. The physical therapists began to alter the therapy goals to realistic and obtainable goals that were less aggressive so to build mastery skills.

The affective process was another key element aggravated by aggressive physical therapy techniques. The affected process with the chronic pain patient can be a primitive reaction to 
stimulation occurring before the typical cognitive processes can consider the formation of a more complex emotion. In other words, the staff began to notice at the suggestion of physical therapy, patients would reply "that's only going to make my pain worse". This was the primitive reaction process as patients related their minimal daily activities as causing more pain. This accelerated as they contemplated an aggressive physical therapy exercise session. The physical therapists confronted this reaction with assistance in the interpretation that these are normal psychological responses as result of the individual's current state of debility. It is vital in such situations to provide motivational reinforcement within the affective process to restore levels of self-efficacy. This was done by educating patients on the fact that their muscles had debilitated and restoration process would be encountered by some pain. To assist in reducing this negative response to physical therapy, a less aggressive therapy program was ordered and a temporary increase in the pill count was made. Coping skills introduced in the educational piece of the patients' encounters through the program assisted their goal completion in physical therapy and their home exercise program thus, further supporting the psychological persuasion of self-efficacy (Bandura, 1977).

\section{Conclusion}

The problem of chronic pain management has clearly been identified as a major health issue in the United States. Despite state legislative mandates, rural areas do not have the necessary manpower to alleviate this problem. A multidisciplinary pain management center implemented via a nonprofit critical access hospital in rural, WV was established based upon evidence based practice guidelines. The effectiveness of this program on the outcomes of selfreported pain, QOL, depression, and anxiety has been determined to be statistically significant. Extensive dissemination of this information is imperative to the implementation of empirical change. This change in the way WV manages chronic pain under current mandated regulations 
can reduce deadly outcomes, provide holistic healthcare, and restore physical and mental health for CNCP patients. 
Appendix A Characteristic Table

Table 1

\begin{tabular}{|c|c|c|c|c|c|c|c|c|c|c|}
\hline Citation & Type & $\begin{array}{l}\text { Risk } \\
\text { Stratification } \\
\text { HP }\end{array}$ & $\begin{array}{l}\text { Informed } \\
\text { Consent }\end{array}$ & $\begin{array}{l}\text { Management } \\
\text { Agreement }\end{array}$ & $\begin{array}{l}\text { Initiation/ } \\
\text { Titration/Break } \\
\text { through }\end{array}$ & Monitoring & $\begin{array}{l}\text { Adverse } \\
\text { Effects }\end{array}$ & $\begin{array}{l}\text { Multidisciplinary } \\
\text { Approaches } \\
\text { Consultation }\end{array}$ & $\begin{array}{l}\text { Driving } \\
\text { and } \\
\text { Safety }\end{array}$ & PCP \\
\hline $\begin{array}{l}\text { APS \& AAPM, } \\
2009\end{array}$ & $\mathrm{CG}$ & $\mathrm{x}$ & $x$ & $x$ & $x$ & $x$ & $x$ & $\mathrm{x}$ & $x$ & $x$ \\
\hline $\begin{array}{l}\text { Management of } \\
\text { Opioid Therapy } \\
\text { for Chronic Pain } \\
\text { Working Group, } \\
2010\end{array}$ & $\mathrm{CG}$ & $x$ & $x$ & $x$ & $x$ & $x$ & $x$ & $x$ & & \\
\hline $\begin{array}{l}\text { Washington State } \\
\text { Agency Medical } \\
\text { Directors' Group, } \\
2010\end{array}$ & $\mathrm{CG}$ & $x$ & $x$ & $x$ & $x$ & $x$ & $x$ & $x$ & & \\
\hline $\begin{array}{l}\text { Work Loss Data } \\
\text { Institute, } 2013\end{array}$ & $\mathrm{CG}$ & $x$ & & $x$ & & & $x$ & $x$ & & \\
\hline $\begin{array}{l}\text { Hooten et al., } \\
2013\end{array}$ & $\mathrm{CG}$ & $x$ & $x$ & $x$ & $x$ & $x$ & $x$ & $x$ & & \\
\hline SIGN, 2013 & $\mathrm{CG}$ & & & & & $x$ & $x$ & $x$ & & \\
\hline $\begin{array}{l}\text { University of } \\
\text { Michigan Health } \\
\text { System, } 2011\end{array}$ & CG & $\mathrm{x}$ & & & $x$ & $\mathrm{x}$ & $x$ & $x$ & & \\
\hline $\begin{array}{l}\text { Colorado Division } \\
\text { of Workers' } \\
\text { Compensation, } \\
2011\end{array}$ & $\mathrm{CG}$ & $x$ & & $\mathrm{x}$ & & $x$ & $x$ & $x$ & & \\
\hline $\begin{array}{l}\text { Manchikanti etal., } \\
2012 \text { (ASIPP) }\end{array}$ & $\mathrm{CG}$ & $\mathrm{x}$ & & $x$ & $x$ & $x$ & $x$ & $x$ & & \\
\hline $\begin{array}{l}\text { ASA Task Force } \\
\text { on Chronic Pain } \\
\text { Management, } \\
\text { ASRA and Pain } \\
\text { Medicine, } 2010\end{array}$ & $\mathrm{CG}$ & $x$ & & & & $x$ & $x$ & $x$ & & $x$ \\
\hline
\end{tabular}


Table 2 Methodological Qualities of Clinical Guidelines

\begin{tabular}{|c|c|c|c|c|c|c|c|c|c|c|}
\hline DOMAIN & $\begin{array}{l}\text { ASA } \\
2010\end{array}$ & $\begin{array}{l}\text { WA } \\
2010\end{array}$ & $\begin{array}{l}\text { CO } \\
2011\end{array}$ & $\begin{array}{l}\text { UM } \\
2011\end{array}$ & $\begin{array}{l}\text { VA } \\
2010\end{array}$ & $\begin{array}{l}\text { SIGN } \\
2013\end{array}$ & $\begin{array}{l}\text { HOOTEN } \\
2013\end{array}$ & $\begin{array}{l}\text { WORK } \\
\text { LOSS } \\
2013 \\
\end{array}$ & $\begin{array}{l}\text { MANCHIKANTI } \\
2012\end{array}$ & $\begin{array}{l}\text { APS } \\
\text { AAPM } \\
2009\end{array}$ \\
\hline Overall objectives & 2 & 3 & 3 & 4 & 4 & 2 & 4 & 3 & 5 & 5 \\
\hline Clinical questions & 2 & 3 & 3 & 2 & 4 & 2 & 2 & 2 & 5 & 5 \\
\hline Patient specific & 3 & 4 & 3 & 3 & 4 & 3 & 4 & 3 & 4 & 5 \\
\hline $\begin{array}{l}\text { Scope \& } \\
\text { Purpose }\end{array}$ & 2.3 & 3.3 & 3 & 3 & 4 & 2.3 & 3.3 & 2.6 & 4.66 & 5 \\
\hline $\begin{array}{l}\text { Relevant } \\
\text { professional } \\
\text { groups }\end{array}$ & 3 & 3 & 2 & 3 & 3 & 3 & 2 & 4 & 5 & 6 \\
\hline $\begin{array}{l}\text { Sought patient } \\
\text { views }\end{array}$ & 0 & 0 & 1 & 1 & 1 & 3 & 1 & 1 & 3 & 4 \\
\hline $\begin{array}{l}\text { Defined target } \\
\text { users }\end{array}$ & 3 & 4 & 4 & 3 & 3 & 3 & 4 & 3 & 3 & 4 \\
\hline $\begin{array}{l}\text { Piloted among } \\
\text { target users }\end{array}$ & 1 & 1 & 1 & 2 & 1 & 3 & 1 & 1 & 2 & 3 \\
\hline $\begin{array}{l}\text { Stakeholder } \\
\text { Involvement }\end{array}$ & 1.75 & 2 & 2 & 2.25 & 2 & 3 & 2 & 2.25 & 3.25 & 4.25 \\
\hline $\begin{array}{l}\text { Systematic } \\
\text { Methods }\end{array}$ & 4 & 3 & 3 & 4 & 3 & 5 & 4 & 3 & 5 & 6 \\
\hline Selection Criteria & 4 & 3 & 4 & 4 & 2 & 5 & 4 & 2 & 4 & 6 \\
\hline $\begin{array}{l}\text { Formulation } \\
\text { Methods }\end{array}$ & 3 & 3 & 3 & 3 & 3 & 5 & 4 & 2 & 4 & 6 \\
\hline $\begin{array}{l}\text { Benefits, risks, } \\
\text { side effects }\end{array}$ & 2 & 3 & 2 & 3 & 3 & 4 & 4 & 2 & 5 & 6 \\
\hline Explicit links & 1 & 1 & 2 & 1 & 1 & 3 & 3 & 1 & 2 & 3 \\
\hline External reviews & 1 & 1 & 2 & 1 & 1 & 4 & 3 & 2 & 2 & 3 \\
\hline Updating & 1 & 1 & 1 & 1 & 1 & 2 & 2 & 1 & 1 & 2 \\
\hline $\begin{array}{l}\text { Rigor of } \\
\text { Development }\end{array}$ & 2.14 & 2.1 & 2.4 & 2.4 & 2 & 4.0 & 3.4 & 1.85 & 3 & 4.57 \\
\hline $\begin{array}{l}\text { Recommendations } \\
\text { specific \& } \\
\text { unambiguous }\end{array}$ & 3 & 4 & 4 & 3 & 3 & 4 & 4 & 3 & 5 & 5 \\
\hline $\begin{array}{l}\text { Different options } \\
\text { with clarity }\end{array}$ & 3 & 3 & 4 & 3 & 3 & 4 & 4 & 2 & 5 & 6 \\
\hline $\begin{array}{l}\text { Key } \\
\text { recommendations }\end{array}$ & 3 & 3 & 3 & 4 & 3 & 3 & 3 & 2 & 5 & 6 \\
\hline Guideline support & 3 & 3 & 3 & 3 & 3 & 4 & 2 & 2 & 3 & 5 \\
\hline $\begin{array}{l}\text { Clarity and } \\
\text { Presentation }\end{array}$ & 3 & 3.25 & 3.5 & 3.25 & 3 & 3.75 & 3.25 & 2.25 & 4.5 & 5.5 \\
\hline $\begin{array}{l}\text { Potential barriers } \\
\text { in application }\end{array}$ & 3 & 2 & 3 & 2 & 4 & 2 & 3 & 2 & 3 & 5 \\
\hline Cost implications & 2 & 2 & 1 & 1 & 2 & 1 & 3 & 2 & 3 & 4 \\
\hline Monitoring/Audit & 1 & 4 & 1 & 1 & 2 & 1 & 2 & 2 & 3 & 3 \\
\hline Applicability & 1 & 2.6 & 1.6 & 1.3 & 2.6 & 1.3 & 2.6 & 2 & 3 & 4 \\
\hline $\begin{array}{l}\text { Editorial } \\
\text { Independence }\end{array}$ & 3 & 3 & 3 & 3 & 3 & 3 & 3 & 3 & 3 & 4 \\
\hline $\begin{array}{l}\text { Conflict of } \\
\text { Interest } \\
\text { Recorded }\end{array}$ & 4 & 2.5 & 1 & 3 & 3 & 4 & 3 & 3 & 3 & 4 \\
\hline Overall Score & 2 & 4 & 2 & 3 & 4 & 2 & 4 & 3.5 & 4 & 6 \\
\hline
\end{tabular}


Table 3 Second Literature Review Article Interventions and Outcomes

\begin{tabular}{|c|c|c|c|c|c|c|c|c|c|c|c|c|}
\hline Article & $\begin{array}{l}\text { Multidisciplinary } \\
\text { Interventions }\end{array}$ & Narcotics & QOL & $\begin{array}{l}\text { Significant } \\
\text { Improvement }\end{array}$ & Anxiety & $\begin{array}{l}\text { Significant } \\
\text { Improvement }\end{array}$ & Depression & $\begin{array}{l}\text { Significant } \\
\text { Improvement }\end{array}$ & Pain & $\begin{array}{l}\text { Significant } \\
\text { Improvement }\end{array}$ & $\begin{array}{l}\text { Physical } \\
\text { Function }\end{array}$ & $\begin{array}{l}\text { Significant } \\
\text { Improvemen }\end{array}$ \\
\hline $\begin{array}{l}\text { RCT } \\
\text { Skevington } \\
\text { et al. 2001 }\end{array}$ & $\mathrm{X}$ & & $\mathrm{X}$ & $\mathrm{X}$ & $\mathrm{x}$ & $\mathrm{T}_{\mathrm{P}} \mathrm{x}$ & $\mathrm{X}$ & $\mathrm{X}$ & $\mathrm{X}$ & $\mathrm{X}$ & - & - \\
\hline $\begin{array}{l}\text { RCT Tait et } \\
\text { al. } 1988\end{array}$ & $\mathrm{X}$ & & - & - & $\mathrm{x}$ & $\mathrm{x}$ & $\mathrm{x}$ & $\mathrm{x}$ & $\mathrm{X}$ & $\mathrm{x}$ & $\mathrm{x}$ & $\mathrm{X}$ \\
\hline $\begin{array}{l}\text { SR } \\
\text { Chaparro et } \\
\text { al, } 2013\end{array}$ & & $\mathrm{X}$ & & & & & & & $\mathrm{X}$ & $\mathrm{X}$ & $\mathrm{X}$ & $\mathrm{X}$ \\
\hline $\begin{array}{l}\text { SR Noble et } \\
\text { al, } 2010\end{array}$ & & $\mathrm{X}$ & $\mathrm{X}$ & - & & & & & $\mathrm{X}$ & $\mathrm{X}$ & $\mathrm{X}$ & - \\
\hline $\begin{array}{l}\text { SR Kamper } \\
\text { et al, } 2014\end{array}$ & $\mathrm{X}$ & & $\mathrm{X}$ & inconclusive & $\mathrm{x}$ & inconclusive & $\mathrm{x}$ & - & $\mathrm{X}$ & $\mathrm{X}$ & $\mathrm{X}$ & $\mathrm{x}$ \\
\hline $\begin{array}{l}\text { RCT } \\
\text { Smeeding et } \\
\text { al. } 2010\end{array}$ & $\mathrm{X}$ & & $\mathrm{X}$ & $\mathrm{x}$ & $\mathrm{x}$ & $\mathrm{x}$ & $\mathrm{X}$ & $\mathrm{X}$ & $\mathrm{X}$ & $\mathrm{X}$ & & \\
\hline $\begin{array}{l}\text { RCT Joos et } \\
\text { al. } 204\end{array}$ & $\mathrm{x}$ & & $\mathrm{X}$ & $\mathrm{x}$ & $\mathrm{x}$ & $\mathrm{x}$ & $\mathrm{x}$ & $\mathrm{x}$ & $\mathrm{X}$ & $\mathrm{x}$ & & \\
\hline $\begin{array}{l}\text { RCT } \\
\text { Dysvik et al. } \\
2004\end{array}$ & $\mathrm{X}$ & & $\mathrm{X}$ & $\mathrm{x}$ & & & & & $\mathrm{X}$ & $\mathrm{x}$ & & \\
\hline
\end{tabular}




\section{References}

Abdulla, A., Adams, N., Bone, M., Elliott, A., Gaffin, J., Jones, D., ... Schofield, P. (2013). British Geriatric Society. Guidance on the management of pain in older people. Age Ageing, 42(suppl 1):i1-i57.

American College of Occupational and Environmental Medicine. (2008). Guidelines for Chronic Use of Opioids. Elk Grove Village, IL: American College of Occupational and Environmental Medicine.

American Geriatric Society Panel on Persistent Pain in Older Persons. (2002). The management of persistent pain in older persons. Journal of the American Geriatrics Society, 50, S205-24. American Society of Anesthesiologists (ASA)Task Force on Chronic Pain Management, American Society of Regional Anesthesia (ASRA) and Pain Medicine. (2010).

Practice guidelines for chronic pain management: an updated report by the ASA Task Force on Chronic Pain Management and the ASRA and Pain Medicine. Anesthesiology, 112(4), 810-33.

American Pain Society (APA) \& American Academy of Pain Management (AAPM). (2009).

Guideline for the use of chronic opioids therapy in chronic noncancerous pain. Journal of Pain, 10 (2), 1-208.

Andersson, H. (2009). Increased mortality among individuals with chronic widespread pain relates to lifestyle factors: a prospective population-based study. Disability and Rehabilitation, 31, 1980-1987.

Ataoğlu, E., Tiftik, T., Kara, M., Tunç, H., Ersöz, M., \& Akkuş, S.(2013). Effects of chronic pain on quality of life and depression in patients with spinal cord injury. Spinal Cord, 51(1),23-6. Atkinson, T., Schatman, M., \& Fudin, J. (2014). The damage done by the war on opioids: the 
pendulum has swung too far. Journal of Pain Research, 7, 265-268.

Bandura, A. (1977). Self-efficacy: toward a unifying theory of behavioral change. Psychological Review, 84, 191-215.

Beck, A., T., Epstein, N., Brown, G., \& Steer, R., A. (1988). An inventory for measuring clinical anxiety: Psychometric properties. Journal of Consulting and Clinical Psychology, 56(6), 893-897.

Beck, A. T., Steer, R. A., \& Garbin, M. G. J. (1988). Psychometric properties of the Beck Depression Inventory Twenty-five years of evaluation. Clinical Psychology Review 8: 77-100.

Breivik, H., Collett, B., Ventafridda, V., Cohen, R., \& Gallacher, D. (2006). Survey of chronic pain in Europe: prevalence, impact on daily life, and treatment. European Journal of Pain, 10, 287-333.

Brouwers, M., Kho, M. E., Browman, G. P., Burgers, J. S., Cluzeau, F., Feder, G., ... Zitzelsberger, L. (2010). AGREE II: Advancing guideline development, reporting and evaluation in healthcare. Canadian Medical Association Journal, 182 (18), 3942.

doi:10.1503/cmaj.090449

Butler, S.F., Budman, S.H., Fernandez, K., \& Jamison, R.N. (2004). Validation of a screener and opioid assessment measure for patients with chronic pain. Pain, 112, $65-75$.

Butler, S., Budman, S., Fernandez, K., Houle, B., Benoit, C., Katz, N., \& Jamison, R. (2007). Development and validation of the current opioid misuse measure. Pain, 130(1-2): 144-156. Retrieved October 15, 2014, from 
http://www.ncbi.nlm.nih.gov/pmc/articles/PMC1950245/

Centers for Disease Control and Prevention. (2016). CDC Guideline for Prescribing

Opioids for Chronic Pain-United States. Retrieved April 15, 2016, from

https://www.cdc.gov/mmwr/volumes/65/rr/pdfs/rr6501e1.pdf

Chaparro, L., Furlan ,A., Deshpande, A., Mailis-Gagnon, A., Atlas, S., \& Turk, D. (2013).

Opioids compared to placebo or other treatments for chronic low-back pain. The

Cochran Collaboration, 8(8), 1-22.

Chou, R., Qaseem, A., Snow, V., Casey, D., Cross, J., Shekelle, P., \& Owens, D. (2007).

Clinical Efficacy Assessment Subcommittee of the American College of Physicians; American College of Physicians; American Pain Society Low Back Pain Guidelines Panel. Diagnosis and treatment of low back pain: a joint clinical practice guideline from the American College of Physicians and the American Pain Society. Annals of Internal Medicine, 147(7), 478-491.

Chrvala, C. (2011). Easing the burden of chronic pain. Retrieved October 15, 2014, from http://www.medpagetoday.com/resource-center/pain-management/chronic pain/a/35139

Cleeland, C., S. (1989). Measurement of pain by subjective report. In: Chapman, C.R., \& Loeser, J. D., eds. Issues in Pain Measurement. New York: Raven Press; pp. 391-403, Advances in Pain Research and Therapy. (1989) 12.

Colorado Division of Workers' Compensation. (2011). Chronic pain disorder medical treatment guidelines. Denver (CO): Colorado Division of Workers' Compensation, 12, pg. 110.

Davidson, M., Tripp, D., Fabrigar, L., \& Davidson, P. (2008). Chronic pain assessment: 
A seven-factor model. Pain Research \& Management, 13(4): 299-308.

Dysvik, E., Vinsnes, A. G., \& Eikeland, O. (2004). The effectiveness of a multidisciplinary pain management programme managing chronic. International Journal of Nursing Practice, 10, 224-234.

Ellert, U., \& Kurth, B. (2013). Health related quality of life in adults in Germany.

Retrieved February 05, 2015, from http://edoc.rki.de/oa/articles/reYqEXVaXguCI/PDF/26WikoOm6xdiI.pdf

A European Consensus Report. ( 2010). Pain proposal improving the current and future management of chronic pain. Retrieved October 25, 2014, from http://www.efic.org/userfiles/file/pain_proposal.pdf.

Federation of State Medical Boards of the United States, Inc. (2005). Model policy for the use of controlled substances for the treatment of pain. Journal of Pain and Palliative Care Pharmacotherapy, 19(2), 73-78.

Fine, P. G. (2012). Treatment guidelines for the pharmacological management of pain in older persons. Pain Medicine, 13(suppl 2), S57-S66.

Fine, P. G., \& Portenoy, R. K. (2009). Ad Hoc Expert Panel on Evidence Review and Guidelines for Opioid Rotation. Establishing "best practices” for opioid rotation: conclusions of an expert panel. The Journal of Pain and Symptom Management, $38,418-25$.

Fisher, C. (2009). Center for Epidemiologic Studies Depression Scale (CES-D): An Excellent Free Psychological Screening Instrument for Major Depression. Retrieved March 1, 2014 from http://www.bmedreport.com/wp-content/uploads/2009/11/CES D-Standford-Version.pdf 
Fredheim, O. M., Kaasa, S., Fayers, P., Saltnes, T., Jordhoy, M., \& Borchgrevink, P.C. (2008). Chronic non-malignant pain patients report as poor health-related quality of life as palliative cancer patients. Acta Anaesthesiologica Scandinavica, 52(1),143148.

Furlan, A. D., Reardon, R., \& Weppler, C. (2010). National Opioid Use Guideline Group. Opioids for chronic noncancer pain: a new Canadian practice guideline. Canadian Medical Association Journal, 182, 923-30.

Geisser, M., E., Roth, R., S., \& Robinson, M., E. (1997). Assessing depression among persons with chronic pain using the Center for Epidemiological Studies-Depression Scale and the Beck Depression Inventory: a comparative analysis. Clinical Journal of Pain, 13(2),163-70.

Global Industry Analysts, Inc. Report. (2011). Retrieved October 19, 2014, from http://www.prweb.com/pdfdownload/8052240.pdf.

Geneen, L., Smith, B., Clarke, C., Martin, D., Colvin, L.A., Moore, R. A. (2014). Physical activity and exercise for chronic pain in adults: an overview of Cochrane reviews (Protocol). Cochrane Database of Systematic Reviews Issue 8. Art. No.: CD011279. doi: 10.1002/14651858.CD011279.

Hann, D., Winter, K., \& Jacobsen, P. (1999). Measurement of depressive symptoms in cancer patients: Evaluation of the center for epidemiological studies depression scale (CES-D). Journal of Psychosomatic Research, 46(5), 437-443.

Hardt, J., Jacobsen, C., Goldberg, J., Nickel, R., \& Buchwald, D. (2008). Prevalence of chronic pain in a representative sample in the United States. Pain Medicine, 9:803812. 
Hoffman, B., Papas, R., Chatkoff, D., \& Kerns, R. (2007). Meta-analysis of psychological interventions for chronic low back pain. Health Psychology, 26(1), 1-9. Retrieved March 19, 2015, from http://dx.doi.org/10.1037/0278-6133.26.1.1

Hoffman, P., Meier, B., \& Council, J. (2002). A comparison of chronic pain between an urban and rural population. Journal of Community Health Nursing. 19(4), 21324.

Hooten, W., M., Timming, R., Belgrade, M., Gaul, J., Goertz, M., Haake, B., ... Walker, N. (2013). Assessment and management of chronic pain. Bloomington (MN): Institute for Clinical Systems Improvement (ICSI), 11, 105.

Institute of Medicine (2011a). Report from the Committee on Advancing Pain Research, Care, and Education. Relieving Pain in America, A Blueprint for Transforming Prevention, Care, Education and Research. Washington, DC: National Academies Press (US). Retrieved October 25, 2014, from http://books.nap.edu/openbook.php?record_id=13172\&page=1

Institute of Medicine, (2011b). Chronic pain-report belief. Retrieved October 27, 2014, from http://www.iom.edu/Reports/2011/Relieving-Pain-in-America-A-Blueprint-for$\underline{\text { Transforming-Prevention-Care-Education-Research/Report-Brief.aspx }}$

Johannes, C., Le, T., Zhou, X., Johnston, J., \& Dworkin, R. (2010). The prevalence of chronic pain in United States adults: results of an internet-based survey. Journal of Pain, 11, 1230-1239.

Joint Commission on Accreditation of Healthcare Organizations. (2006). Comprehensive accreditation manual for ambulatory care. Oakbrook Terrace, IL: Joint Commission on Accreditation of Healthcare Organizations. 
Jones, C., Mack, K., \& Paulozzi, L. (2010). Pharmaceutical overdose deaths, United States. JAMA, 309(7), 657-659.

Joos, B., Uebelhart, D., Michel, B., \& Sprott, H. (2004). Influence of an outpatient multidisciplinary pain management program on the health-related quality of life and the physical fitness of chronic pain patients. Journal of Negative Results in BioMedicine. 3:1.

Kaiser Family Foundation (2011). Costs / Insurance. Retrieved September 15, 2014 from http://facts.kff.org/results.aspx?view=slides\&topic=3

Kamper, S. J., Apeldoorn, A. T., Chiarotto, A. R., Smeets, J.E., Ostelo, R., Guzman, J., \& van Tulder, M.W. (2014). Multidisciplinary biopsychosocial rehabilitation for chronic low back pain. Cochrane Database of Systematic Reviews (9). doi:10.1002/14651858.CD000963.pub3.Kroenke, K., Yu, Z., Wu, J., Kean, J., \&

Larrabee, J.H. (2009). Nurse to nurse: evidence-based practice. McGraw Hill: New York, NY.

LeFort,S., \& Hannah, T. (1994). Return to work following an aquafitness and muscle strengthening program for the low back injured. Archives of Physical Medicine and Rehabilitation, 75(11), 1247-55.

Lepine, J., \& Briley, M. (2004). The epidemiology of pain in depression. Human Psychopharmacology, 19, S3-S7.

Lynch, M., Campbell, F., Clark, A., Dunbar, M., Goldstein, D., Peng, P., ...Tupper, H. (2008). A systematic review of the effect of waiting for treatment for chronic pain. Pain, 136 (1-2), 97-116. 
Makris, U., Abrams, R., Gurland, B., \& Reid, M. (2014). Management of persistent pain in the older patient : a clinical review. JAMA, 312(8),825-836.

doi:10.1001/jama.2014.9405

Management of Opioid Therapy for Chronic Pain Working Group. (2010). VA/DoD clinical practice guideline for management of opioid therapy for chronic pain. Washington (DC): Department of Veterans Affairs, Department of Defense, 5, 159.

Manchester City Council. (2016). Beck Anxiety Inventory Questionnaire. Retrieved March 1, 2014 from www.manchester.gov.uk/download/downloads/id/19269/ $\underline{\text { beck_anxiety_inventory_questionnaire.pdf beck anxiety inventory online }}$

Manchikanti, L., Abdi, S., Atluri. S., Balog, C., Benyamin, R., Boswell, M., ... Wargo, B. (2012). American Society of Interventional Pain Physicians (ASIPP) guidelines for responsible opioid prescribing in chronic non-cancer pain: part 2 - guidance. Pain Physician, 15(3), S67-S116.

Marley, J., Tully, M., Porter-Armstrong, A., Bunting, B., O’Hanlon, J., \& McDonough, S. (2014). A systematic review of interventions aimed at increasing physical activity in adults with chronic musculoskeletal pain - protocol. Systematic Reviews, 3,106. Retrieved September 15, 2014 from http://www.systematicreviewsjournal.com/content/3/1/106

McBeth, J., Symmons, D., Silman, A., Allison, T., Webb, R., Brammah, T., \& Macfarlane, G. (2009). Musculoskeletal pain is associated with a long-term increased risk of cancer and cardiovascular-related mortality. Rheumatology (Oxford) 48, 7477. 
McHorney, C.A., Ware, J.E., Lu, J.F.R., \& Sherbourne, C.D. (1994). The MOS 36-Item Short-Form Health Survey (SF-36®): III. Tests of data quality, scaling assumptions and reliability across diverse patient groups. Medical Care, 32(4), 40-66.

Melzack, R. (1975a). The McGill Pain Questionnaire: major properties and scoring methods, Pain, 1, 275-299.

Melzack, R. (1975b). The McGill Pain Questionnaire. Retrieved March 1, 2014 from http://www.rehabmeasures.org/Lists/RehabMeasures/DispForm.aspx? ID=1111

Monahan, P. (2014). Operating characteristics of PROMIS four-item depression and anxiety scales in primary care patients with chronic pain. Pain Medicine, 19(8).doi: $10.1111 / \mathrm{pme} .12537$

Morley-Forster, P., Pergolizzi, J., Taylor, R. Jr., Axford-Gatley, R., \& Sellers, E. (2013). Mitigating the risk of opioid abuse through a balanced undergraduate pain medicine curriculum journal of pain. Research Journal of Pain Research, 6, 791-801.

Nash, V. R., Ponto, J., Townsend, C., Nelson, P., \& Bretz, M.N.(2013). Cognitive behavioral therapy, self-efficacy, and depression in persons with chronic pain. Pain Management Nursing Journal. 14(4),e236-43.

Noble, M., Treadwell, J. R., Tregear, S. J., Coates, V. H., Wiffen, P. J., Akafomo, C., \& Schoelles, K. M. (2010). Long-term opioid management for chronic noncancer pain. Cochrane Database of Systematic Reviews, Issue 1. Art. No.: CD006605. doi:10.1002/14651858.CD006605.pub2.

Nuckols, T., Anderson, M., Popescu, I., Diamant, A., Doyle, B., Capua, P., \& Chou, R. (2014). Opioid prescribing: a systematic review and critical appraisal of guidelines for chronic pain. Annals of Internal Medicine, 160, 38-47. 
Optum Incorpation. (2016). SF-36v2 Health Survey. Retrieved March 1, 2014 from https://campaign.optum.com/optum-outcomes/what-we-do/health-surveys/sf-36v2health-survey.html

Passik, S. D., Schein, J. R., Dodd, S. L., et al. (2002). A new tool to assess and document pain outcomes in chronic pain patients receiving opioid therapy. Lexington KY: University of Kentucky.

Portenoy, R., Ugarte, C., Fuller, I., \& Haas, G. (2004). Population-based survey of pain in the United States: differences among white, African American, and Hispanic subjects. Journal of Pain, 5,317-328.

Radloff, L., S. (1977). The CES-D scale: A self-report depression scale for research in the general population. Applied Psychological Measurement, 1, 385-401.

Rolfs, R. T., Johnson, E., Williams, N. J., \& Sundwall, D.N. (2010).Utah Department of Health. Utah clinical guidelines on prescribing opioids for treatment of pain. Journal of Pain and Palliative Care Pharmacotherapy, 24,219-35.

Rosswurm, M. A. \& Larrabee, J.H. (1993). A model for change to evidence-based practice. Image Journal of Nursing Scholarship, 31(4),317-22.

Schappert, S., \& Burt, C. Ambulatory care visits to physician offices, hospital outpatient departments, and emergency departments: United States, 2001-02. Vital Health Stat 13, 2(159), 1-66.

Schlosser, R. W. (2007). Appraising the quality of systematic reviews. Focus: A publication of the National Center for the Dissemination of Disability Research, Brief No. 17. 
Retrieved May 15, 2011, from

http://www.ncddr.org/kt/products/focus/focus17/Focus17.pdf

Scottish Intercollegiate Guidelines Network (SIGN). (2013). Management of chronic pain: a national clinical guideline. Edinburgh (Scotland): SIGN, 12, pg. 64.Sessle, B. (2011) Unrelieved pain: a crisis. Pain Research \& Management 16(6), 416-420.

Skevington, S. M., Carse, M. S., \& Williams, A.C. (2001). Validation of the WHOQOL 100: Pain management improves quality of life for chronic pain patients. The Clinical Journal of Pain. 17,264-275.

Smeeding, S., Bradshaw, D., Kumpfer, K., Trevithick, S., \& Stoddard, G. (2010).

Outcome evaluation of the Veterans Affairs Salt Lake City Integrative Health Clinic for chronic pain and stress-related depression, anxiety, and post-traumatic stress disorder. The Journal of Alternative and Complementary Medicine; 16 (8), 823-835.

Tait, C.R., Duckro, P. N., Margolis, R., B., \& Wiener, R. (1988). Quality of life following treatment: Outpatients with chronic pain. International Journal of Psychiatry in Medicine.18(3), 271-282.

Takai, Y., Yamamoto-Mitani, N., Abe, Y, \& Suzuki, M. (2014). Literature review of pain management for people with chronic pain. Journal of Nursing Science. 7(19). doi: 10.1111/jjns. 12065

Tsai, C., Bayliss, M.S., \&Ware, J. E. (1997). SF-36® health survey annotated bibliography: Second edition (1988-1996). Boston, MA: Health Assessment Lab, New England Medical Center.

Tsang, A., Von Korff, M., Lee, S., Alonso, J., Karam, E., Angermeyer, M., ... Watanabe, M. (2008). Common chronic pain conditions in developed and developing countries: 
gender and age differences and comorbidity with depression-anxiety disorders.

Journal of Pain, 9(10), 883-891

Turk, D., Wilson, H., \& Cahana, A. (2011).Treatment of chronic non-cancer pain. Lancet, $377,2226-2235$.

United States Census Bureau, 2012. Retrieved September 05, 2014 from http://www.census.gov/popest/about/terms.html

United States Census Bureau. Retrieved November 1, 2014. http://www.census.gov/prod/www/decennial.html

U.S. Department of Health and Human Services HRSA. Retrieved January 16, 2014 http://www.hrsa.gov/shortage/

University of Michigan Health System. (2011). Managing chronic non-terminal pain in adults including prescribing controlled substances. Ann Arbor (MI): University of Michigan Health System, 1, pg. 36.

Utah Department of Health. (2009). Utah clinical guidelines on prescribing opioids for treatment of pain. Salt Lake City, UT: Utah Department of Health.

Veterans Health Administration, Department of Defense. (2010). VA/DoD clinical practice guideline for the management of opioid therapy for chronic pain.

Washington (DC): Veterans Health Administration, Department of Defense.

Walwyn, W., Miotto, K., \& Evans, C. (2010). Opioid pharmaceuticals and addiction: the issues and research directions seeking solutions. Drug Alcohol Depend, 108(3), 156165.

Ware, J. E., Snow, K. K., Kosinski, M., \& Gandek, B. (1993). SF-36® Health survey 
manual and interpretation guide. Boston, MA: New England Medical Center, The Health Institute.

Washington State Agency Medical Directors' Group. (2010). Interagency guideline on opioid dosing for chronic non-cancer pain: an educational aid to improve care and safety with opioid treatment. Olympia (WA): Washington State Department of Labor and Industries.

Watkins, E., Wollan, P., Melton, L.J. III, \& Yawn, B.P. (2008). A population in pain: report from the Olmsted County health study. Pain Medicine, 9,166-174.

Webster, L. R., \& Webster, R. (2005). Predicting aberrant behaviors in Opioid-treated patients: preliminary validation of the Opioid risk tool. Pain Medicine. 6(6),432

Weiss, K. E., Hahn, A., Wallace, D. P., Biggs, B., Bruce, B. K., \& Harrison T.E. (2013). Acceptance of pain: associations with depression, catastrophizing, and functional disability among children and adolescents in an interdisciplinary chronic pain rehabilitation program. Journal of Pediatric Psychology. 38(7),756-65.

West Virginia State Medical Association (2012). Controlled Substances Bill Biggest Healthcare Issue of Session. Retrieved September 25, 2014 from http://www.wvsma.org/Portals/0/MedAdv_April2012WEB.pdf

Work Loss Data Institute. (2013). Pain (chronic). Encinitas (CA): Work Loss Data Institute, 11, pg. 14.

Zhou, K., Zhuang, G., Zhang, H., Liang, P, Yin, J., Lingling, K., Mengmeng, H., \& Lijuan, Y. (2013). Psychometrics of the short form 36 health survey version 2 (SF-36v2) and 
the quality of life scale for drug addicts (QOL-DAv2.0) in Chinese mainland patients with methadone maintenance treatment. PLoS ONE 8(11), 27-38:

doi:10.1371/journal.pone.0079828. 